\title{
THE HIGH LATITUDE CIRCULATION AND TEMPERATURE STRUCTURE OF THE THERMOSPHERE NEAR SOLSTICE
}

\author{
R. G. ROBLE, R. E. DICKINSON, E. C. RIDLEY and B. A. EMERY \\ National Center for Atmospheric Research,* P.O. Box 3000, Boulder, CO 80307, U.S.A. \\ P. B. HAYS and T. L. KILLEEN \\ Space Physics Research Laboratory, University of Michigan, Ann Arbor, MI 48105, U.S.A. \\ and \\ N. W. SPENCER \\ Goddard Space Flight Center, NASA, Greenbelt, MD 20771, U.S.A.
}

(Received 22 April 1983)

\begin{abstract}
The neutral gas temperature and circulation of the thermosphere are calculated for December solstice conditions near solar cycle maximum using NCAR's thermospheric general circulation model (TGCM). High-latitude heat and momentum sources significantly alter the basic solar-driven circulation during solstice. At $F$-region heights, the increased ion density in the summer hemisphere results in a larger ion drag momentum source for the neutral gas than in the winter hemisphere. As a result there are larger wind velocities and a greater tendency for the neutral gas to follow the magnetospheric convection pattern in the summer hemisphere than in the winter hemisphere. There is about three times more Joule heating in the summer than the winter hemisphere for moderate levels of geomagnetic activity due to the greater electrical conductivity in the summer E-region ionosphere.

The results of several TGCM runs are used to show that at $F$-region heights it is possible to linearly combine the solar-driven and high-latitude driven solutions to obtain the total temperature structure and circulation to within $10-20 \%$. In the lower thermosphere, however, non-linear terms cause significant departures and a linear superposition of fields is not valid.

The $F$-region winds at high latitudes calculated hy the TGCM are also compared to the meridional wind derived from measurements by the Fabry-Perot Interferometer (FPI) and the zonal wind derived from measurements by the Wind and Temperature Spectrometer (WATS) instruments onboard the Dynamics Explorer ( $D E$-2) satellite for a summer and a winter day. For both examples, the observed and modeled wind patterns are in qualitative agreement, indicating a dominant control of high latitude winds by ion drag. The magnitude of the calculated winds $\left(400-500 \mathrm{~m} \mathrm{~s}^{-1}\right)$ for the assumed $60 \mathrm{kV}$ cross-tail potential, however, is smaller than that of the measured winds $\left(500-800 \mathrm{~m} \mathrm{~s}^{-1}\right)$. This suggests the need for an increased ion drag moment um source in the model calculations due to enhanced electron densities, higher ion drift velocities, or some combination that needs to be further defined from the $D E-2$ satellite measurements.
\end{abstract}

\section{INTRODUCTION}

Previous studies of the zonally symmetric circulation and temperature structure of the thermosphere for solstice conditions (Dickinson et al., 1977; Roble et al., 1977) have shown that there is a mean summer-towinter-pole circulation, with the temperature over the summer pole several hundred degrees warmer than over the winter pole. These studies also found that with the inclusion of high-latitude heat sources due to auroral activity, the summer-to-winter pole circulation is reinforced in the summer hemisphere and a reverse

\footnotetext{
* The National Center for Atmospheric Research is
} sponsored by the National Science Foundation. circulation is established in the high-latitude winter hemisphere. The boundary between the two oppositely directed circulations was found to occur at middle to high latitudes in the winter hemisphere, its position being governed by the magnitude of geomagnetic activity. This general pattern for solstice conditions has been confirmed by the studies of Hernandez and Roble (1976), Emery (1978), Babcock and Evans (1979a, b), Oliver (1980) and Sipler et al. (1982).

Various aspects of the three-dimensional circulation, temperature and compositional structure for solstice conditions also have been examined by Mayr and Volland (1972), Straus et al. (1975), Straus and Christopher (1979), Fuller-Rowell and Rees (1980), Rees et al. (1980), and Dickinson et al. (1981). The 
models show considerable cross-equator transport from the summer-to-winter hemisphere, with a more pronounced diurnal temperature variation in the winter than in the summer hemisphere.

Fuller-Rowell and Rees $(1980,1981)$ and Roble et al. (1982) have examined the effect of Joule heating and the ion drag momentum source from magnetospheric convection on the high-latitude circulation and temperature structure of the thermosphere for equinox conditions. These studies showed that magnetospheric convection drives a largely rotational, nondivergent, double-vortex wind system at $F$-region heights that can attain velocities greater than $500 \mathrm{~m} \mathrm{~s}^{-1}$ during moderate levels of geomagnetic activity. These vortices extend downward into the lower thermosphere. However, there is a significant shift of the pattern from that at $F$-region heights and furthermore, a pronounced dawn-to-dusk temperature contrast was found to develop. The overall pattern is generally sunaligned and has a pronounced universal time (U.T.) variation due to the displaced geographic and geomagnetic poles and a slight $\left(\sim 5^{\circ}\right)$ offset of the magnetospheric convection pattern in the antisunward direction from the geomagnetic pole.

In this paper we examine the effect of magnetospheric convection on the circulation and temperature structure of the thermosphere for solstice conditions using the National Center for Atmospheric Research (NCAR) thermospheric general circulation model (TGCM). Because of the larger electron densities in the sunlit summer hemisphere, magnetospheric convection has a stronger control on thermospheric winds than in the dark winter hemisphere where the electron densities are lower. The neutral wind pattern is more closely aligned to the ion drift pattern of magnetospheric convection and the effects penetrate deeper into the lower thermosphere in the summer hemisphere than in the winter hemisphere.

We also perform numerical experiments which show that solar-driven and magnetospheric convectiondriven solutions calculated separately can be linearly combined to approximate the solution containing the combined effects to within $10-20 \%$ at $F$-region heights. The linear combination, however, fails to reproduce the combined pattern below about $150-200 \mathrm{~km}$. These results show that linear models can be used to investigate $F$-region dynamics, whereas nonlinear models are required to investigate the dynamics of the lower thermosphere.

The calculated winds over the summer and winter polar caps are compared to the $F$-region winds measured by the Dynamics Explorer-2 satellite. This comparison shows a general agreement between the calculated and observed wind patterns, both patterns indicating a strong control of the winds by magnetospheric convection. The magnitude of the peak observed winds $\left(\sim 500-800 \mathrm{~m} \mathrm{~s}^{-1}\right)$, however, is larger than that of the model peak winds $(\sim 400-500 \mathrm{~m}$ $\mathrm{s}^{-1}$ ) calculated assuming a $60 \mathrm{kV}$ cross-tail potential in the magnetospheric convection model. Thus, a larger ion drag momentum source would be needed to obtain better agreement between the magnitude of the calculated and observed wind speeds.

\section{MOLEL}

The thermospheric temperature structure and circulation is calculated using the NCAR thermospheric general circulation model (TGCM) as described in detail by Dickinson et al. (1981). The model has a $5^{\circ}$ latitude-by-longitude grid with 24 constant-pressure surface layers in the vertical, extending from approx. 97 to $500 \mathrm{~km}$ altitude. Dickinson et al.(1981) examined the global temperature structure and circulation for both equinox and solstice conditions with prescribed solar extreme ultraviolet (e.u.v.) and ultraviolet (u.v.) heating and with or without the addition of a prescribed highlatitude heat source assumed to be distributed uniformly in longitude. The zonally averaged structure was calculated using the TGCM results and was compared with the results from previous studies of a zonally symmetric thermospheric model (Dickinson $e t$ al., 1975, 1977; Roble et al., 1977). In a subsequent paper, Roble et al. (1982) examined the effect of highlatitude plasma motion due to magnetospheric convection in altering the global circulation and temperature structure of the thermosphere for equinox conditions. The magnetospheric convection pattern is sun-aligned relative to the geomagnetic pole, so it is necessary to include the corotation of ionospheric plasma in the TGCM coordinate system that rotates with the Earth. We use the model of Sojka et al. (1979, 1980), who modified the model of Volland $(1975,1978$, 1979a) to determine the combined plasma motion due to the superimposed magnetospheric convection pattern and corotation at high latitudes. The magnetic field was assumed to be a tilted centered dipole with the North geomagnetic pole located at $78.3^{\circ} \mathrm{N}$ latitude and $291^{\circ} \mathrm{E}$ longitude. Both the Joule heating and ion drag momentum source due to the relative drift between the ions and neutrals are updated at each time step in the model to determine the time-dependent Joule heating rate and momentum forcing.

In the version of the model used here, the neutral composition and ion drag tensor are not calculated selfconsistently. Rather, the background neutral gas composition and global mean temperature structure are determined using the mass spectrometer and 
incoherent scatter (MSIS) model of neutral temperature and composition (Hedin et al., 1977a, b). The ion drag tensor is determined from the empirical model of electron density of Chiu (1975) and the MSIS model of neutral temperature and composition. Both the composition and ion drag tensor are assumed to remain fixed in local time as the Earth rotates. Thus, as formulated here, the ionosphere and composition do not respond to the calculated dynamic structure but remain invariant, corotating with the Earth. Contours giving the global distribution of electron density for December solstice conditions near solar maximum (F10.7 $160 \times 10^{-22} \mathrm{Wm}^{-2} \mathrm{~Hz}^{-1}$ ) are shown in Fig. 1 for 300,200 and $100 \mathrm{~km}$ altitude. In the lower ionosphere, photochemical equilibrium occurs with maximum electron density at the subsolar point and a distribution that varies as the cosine of the solar zenith angle. At $F$-region altitudes the equatorial anomaly is present, with an asymmetry between the summer and winter hemisphere. This pattern is assumed to corotate with the Earth and its electron density values are used to calculate the ion drag in the TGCM.

\section{RESULTS FOR DECEMBER SOLSTICE WITH COINCIDENT POLES}

We first present the calculated temperature and wind results for December solstice assuming coincident geomagnetic and geographic poles. Calculations are made for three cases: (a) solar e.u.v. and u.v. heating alone, (b) solar heating plus magnetospheric convection with a cross-tail potential of $20 \mathrm{kV}$, and (c) solar heating plus magnetospheric convection with a crosstail potential of $60 \mathrm{kV}$. The latter two cases correspond to geomagnetic very quiet conditions $\left(K_{p} \sim 1\right)$ and moderate geomagnetic conditions $\left(K_{p} \sim 3-5\right)$, respectively. The calculated circulation and temperature structure over the Southern Hemisphere summer pole
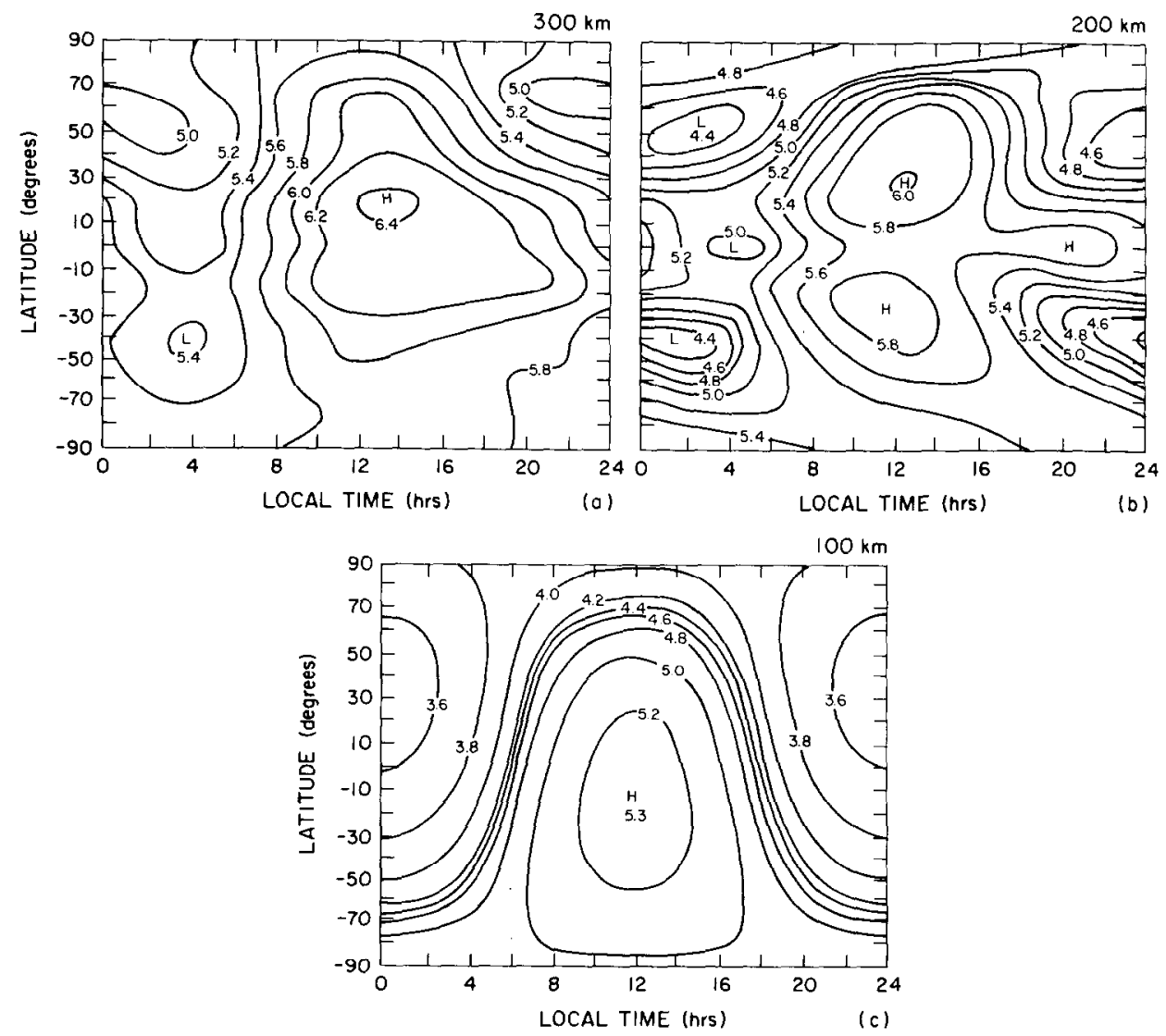

Fig. 1. Contours of Electrun uensity $\left(\log _{10}\left(\mathrm{n}_{\mathrm{e}} ; \mathrm{cm}^{-3}\right)\right)$ AT VARIOUS ALTITUDES: (a) $300 \mathrm{~km}$, (b) $200 \mathrm{~km}$ AND (c) $100 \mathrm{~km}$, OBTAINED FROM THE CHIU (1975) EMPIRICAL ELECTRON DENSITY MODEL THAT ARE USED IN THE TGCM FOR THE DECEMBER SOLSTICE CALCULATIONS $($ F $10.7 \sim 160)$. 
along the $Z=+1$ constant-pressure surface at approx. $300 \mathrm{~km}$ are shown in Fig. 2 for the three cases. The results represent steady-state conditions after five model days of integration time. For the case when solar heating only is considered (Fig. $2 \mathrm{a}$ ) the circulation is from the dayside over the summer pole toward midnight, with wind speeds typically $100 \mathrm{~m} \mathrm{~s}^{-1}$. The calculated contours of perturbation temperature (defined as a departure from a specified global mean temperature at that pressure level implied by solar heating alone) indicate a maximum temperature of $200 \mathrm{~K}$ in the vicinity of the geographic pole, with a larger temperature gradient on the nightside than on the dayside. The wind velocities are greatest in the midnight sector, with speeds approaching $110 \mathrm{~m} \mathrm{~s}^{-1}$. Joule heating occurs in the thermosphere whenever there is a relative drift between the ions and neutrals. For the casc of solar hcating only the ions arc assumed to corotate with the Earth and the neutral winds move relative to this coordinate frame. The calculated total Joule heating due to the relative difference between the ions and neutrals for this case is $2.38 \times 10^{10} \mathrm{~W}$ as indicated in Table 1 as $0 \mathrm{kV}$ cross-tail potential.

The calculated circulation and temperature struc-
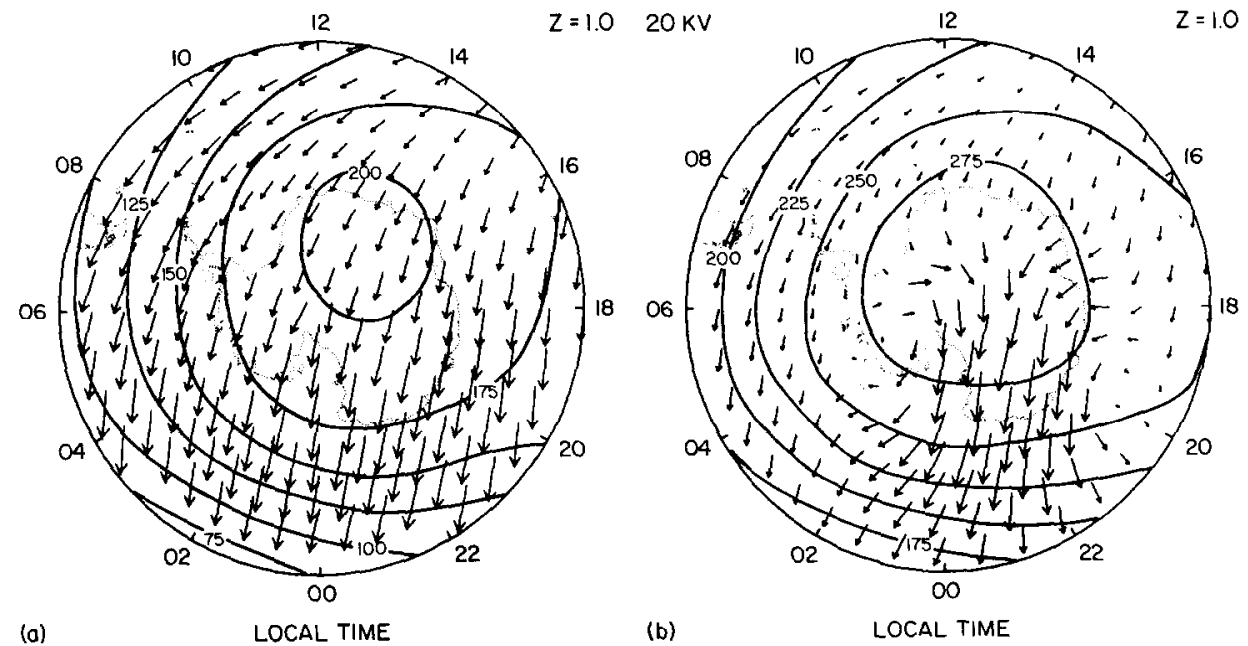

(a)

LOCAL TIME

(b)

$Z=1.0$

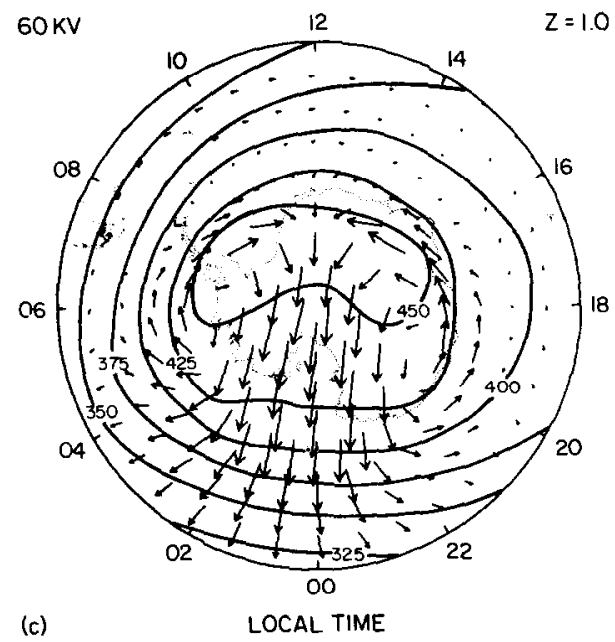

Fig. 2. Polar Plots Giving the direction and Magnitude of THE CalCulated SOUTHERN HEMiSPHERE (SUMMER) HIGH-LATITUDE CIRCULATION AND CONTOURS OF PERTURBATION TEMPERATURE (K) ALONG THE $Z=$ $+1(\sim 300 \mathrm{~km})$ CONSTANT-PRESSURE SURFACE AT DECEMBER SOLSTICE FOR (a) SOLAR HEATING ONLY, (b) SOLAR HEATING PLUS MAGNETOSPHERIC CONVECTION WITH A CROSS-TAIL POTENTIAL OF $20 \mathrm{kV}$ AND (c) SOLAR HEATING PLUS MAGNETOSPHERIC CONVECTION WITH A CROSS-TAIL POTENTIAL OF $60 \mathrm{kV}$.

The wind speed associated with the maximum arrow is $110 \mathrm{~m} \mathrm{~s}^{-1}$ in (a), $200 \mathrm{~m} \mathrm{~s}^{-1}$ in (b) and $380 \mathrm{~m} \mathrm{~s}^{-1}$ in (c), respectively. 
TABLe 1. HemisPheric Joule heating RATE (W)

\begin{tabular}{cccc}
\hline $\begin{array}{c}\text { Cross-tail } \\
\text { potential }\end{array}$ & \multicolumn{1}{c}{ Total } & $\begin{array}{c}\text { Summer } \\
\text { hemisphere }\end{array}$ & $\begin{array}{c}\text { Winter } \\
\text { hemisphere }\end{array}$ \\
\hline $0 \mathrm{kV}$ & $2.38 \times 10^{10}$ & $1.09 \times 10^{10}$ & $1.29 \times 10^{10}$ \\
$20 \mathrm{kV}$ & $2.75 \times 10^{10}$ & $1.40 \times 10^{10}$ & $1.35 \times 10^{10}$ \\
$60 \mathrm{kV}$ & $7.89 \times 10^{10}$ & $5.87 \times 10^{10}$ & $2.02 \times 10^{10}$ \\
$\mathrm{Q}(60 \mathrm{kV})$ & 2.86 & 4.19 & 1.49 \\
\hline $\mathrm{Q}(20 \mathrm{kV})$ & & & \\
\hline
\end{tabular}

ture along the $Z=+1$ constant-pressure surface when the calculations include solar heating, plus Joule heating and a momentum source associated with magnetospheric convection having a cross-tail potential of $20 \mathrm{kV}$, is shown in Fig. 2b. The Joule heating over the summer polar region increases the calculated perturbation temperature from $200 \mathrm{~K}$ for the case of solar heating alone to $275 \mathrm{~K}$ when Joule heating is included. The maximum temperature remains near the geographic pole and the temperature contours are circular in the polar region. The net effect of the Joule heating is to raise the overall temperature over the summer polar region by about $100 \mathrm{~K}$. The total Joulc heating calculated over the summer hemisphere is $1.4 \times 10^{10} \mathrm{~W}$ as indicated in Table 1 .

The ion drag associated with magnetospheric convection increases the antisunward wind speed over the polar cap from $110 \mathrm{~m} \mathrm{~s}^{-1}$ in the solar-driven case to $200 \mathrm{~m} \mathrm{~s}^{-1}$. The ion drift has the two-cell circulation pattern shown in Fig. 1 of Roble et al. (1982). The neutral wind tends to follow the two-cell ion drift pattern. At this relatively low ion convection speed $\left(\sim 300 \mathrm{~m} \mathrm{~s}^{-1}\right)$ for the $20 \mathrm{kV}$ cross-tail potential, the sunward flow at the boundary of the polar cap is not yet established, but the dayside-to-nightside flow in this region is weakened considerably.

The calculated circulation and temperature structure over the summer pole when the cross-tail potential is increased to $60 \mathrm{kV}$ is shown in Fig. $2 \mathrm{c}$. The Joule heat input in the summer hemisphere increases from $1.4 \times 10^{10} \mathrm{~W}$ for the $20 \mathrm{kV}$ case to $5.9 \times 10^{10} \mathrm{~W}$. This increase in Joule heating further raises the pertur. bation temperature over the geographic pole to $450 \mathrm{~K}$. The maximum temperatures occur in a broad region at the throat of the magnetospheric ion convection pattern. The temperature contours have values that decrease equatorward. The greater ion convection velocity $\left(\sim 1 \mathrm{~km} \mathrm{~s}^{-1}\right)$ greatly increases the neutral wind speed through ion drag. The antisunward winds over the polar cap increase from $200 \mathrm{~m} \mathrm{~s}^{-1}$ in the $20 \mathrm{kV}$ case to $380 \mathrm{~m} \mathrm{~s}^{-1}$ for the $60 \mathrm{kV}$ case. In addition, at the boundary of the polar cap the ion drag is sufficient to reverse the direction of the wind to a sunward flow, thus reproducing the pattern of magnetospheric convection. Near local midnight there is an equatorward surge in the wind velocities, an effect that has been observed in the Northern Hemisphere by Bates and Roberts (1977) and Babock and Evans (1979b), using the Chatanika and Millstone Hill radars, respectively. The westward flow in the evening sector has been observed by Meriwether et al. (1973), Nagy et al. (1974), Hays et al. (1979), Rees et al.(1980) and Heppner and Miller (1982).

The empirical electron density model of Chiu (1975), used here to obtain a global distribution of ion drag, gives large electron densities over the summer polar cap, presumably due to continuous daylight during solstice conditions, as shown in Fig. 1. Large electron densities result in a strong coupling between the convecting ions and neutral gas, which is necessary as seen in Fig. 2c for the neutral gas circulation to develop a two-cell pattern similar to the ion convection pattern. Weaker coupling occurs in the winter hemisphere due to much lower model ion densities, as is discussed later.

Figure 3 shows the same fields as Fig. 2 except for the lower thermosphere, along the $Z=-4$ constantpressure surface at approx. $130 \mathrm{~km}$. With solar heating only, the calculated temperature decreases from maximum temperatures near 15.00 L.T. to minimum temperatures near 02.00 L.T., as shown in Fig. 3a. The circulation is also from the high-temperature noon sector toward the midnight sector but with an almost $90^{\circ}$ counterclockwise rotation of the wind vector occurring across the pole. The maximum wind velocities at this level of about $75 \mathrm{~m} \mathrm{~s}^{-1}$ occur in the midnight sector. With the addition of Joule heating and an ion drag momentum source associated with magnetospheric convection having a $20 \mathrm{kV}$ cross-tail potential, a $40 \mathrm{~K}$ temperature contrast between 06.00 L.T. and 18 L.T. develops across the pole, as shown in Fig. 3b. The overall temperature of the polar cap also increases due to Joule heating. The circulation is about the same as for the solar-heating-only case, with a maximum wind speed of $77 \mathrm{~m} \mathrm{~s}^{-1}$.

When the cross-tail potential is increased to $60 \mathrm{kV}$, the temperature contrast intensifies to about $100 \mathrm{~K}$ and Joule heating further raises the temperature of the whole polar cap, as shown in Fig. 3c. In addition, the circulation pattern changes in response to the larger magnetospheric convection ion drift velocities. The maximum wind of $89 \mathrm{~m} \mathrm{~s}^{-1}$ occurs directly over the polar region. On the morning side of the polar cap a clockwise low-temperature vortex develops in the Southern Hemisphere, acting as an obstacle to the general flow from the high-temperature region near 14.00 L.T. to the relatively low-temperature region near local midnight. Magnetospheric convection redirects 


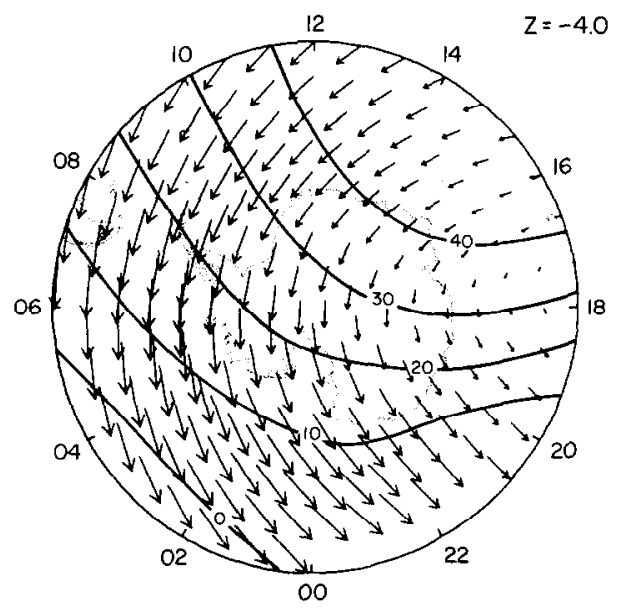

(a)

LOCAL TIME

$$
20 \mathrm{KV}
$$

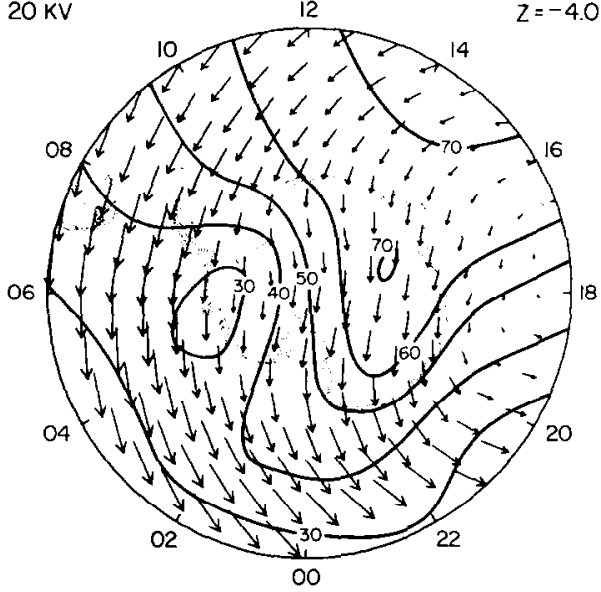

(b)
LOCAL TIME

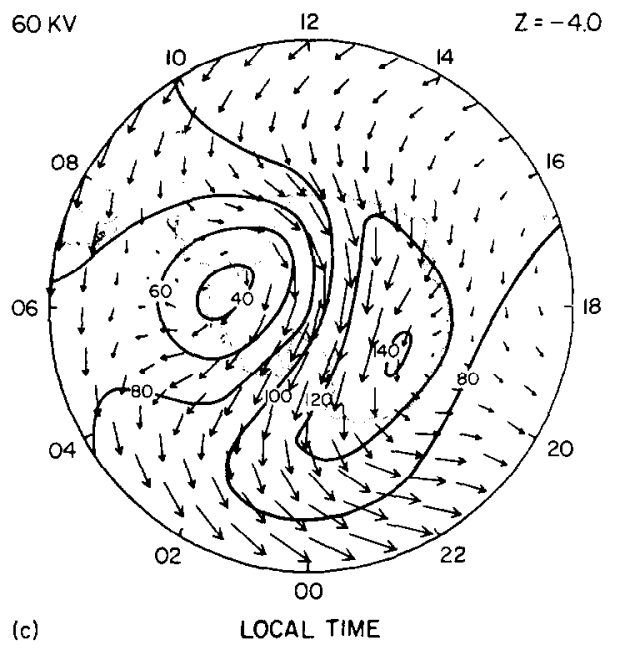

Fig. 3. SAME CAPTION AS IN Fig. 2 EXCEPT ALONG THE $Z=-4(130 \mathrm{~km})$ CONSTANT-PRESSURE SURFACE. The wind speed associated with the maximum arrow is $75 \mathrm{~m} \mathrm{~s}^{-1}$ in (a), $77 \mathrm{~m} \mathrm{~s}^{-1}$ in (b) and $89 \mathrm{~m} \mathrm{~s}^{-1}$ in (c), respectively.

the overall flow pattern, producing a jet over the polar cap.

The calculated temperature structure and circulation along the $Z=+1(300 \mathrm{~km})$ constant-pressure surface in the winter (i.e., northern) hemisphere is shown in Fig. 4 for the same cases considered previously. For the case of solar heating alone (Fig. 4a) the temperature gradient and circulation is from near 14.00 L.T. over the pole to near 02.00 L.T. The temperature decreases steadily from the noon-tomidnight side over the winter polar cap, in contrast to the temperature maximum centered over the summer pole, as shown in Fig. 2. The maximum wind speed is $181 \mathrm{~m} \mathrm{~s}^{-1}$ and there is a counterclock wise turning of the circulation pattern passing from the dayside to the nightside. When Joule heating and the momentum source associated with magnetospheric convection having a cross-tail potential of $20 \mathrm{kV}$ is included (Fig. $4 \mathrm{~b}$ ), the temperature pattern is similar, decreasing over the pole from the noon to the midnight side, but the overall polar cap temperature is raised by about $80 \mathrm{~K}$. The total Joule heating in the Northern Hemisphere for this case is $1.3 \times 10^{10} \mathrm{~W}$. The circulation pattern also remains similar except that the ion drag momentum source increases the wind in the polar cap from $181 \mathrm{~m}$ $\mathrm{s}^{-1}$ for the solar-heating-alone case to $200 \mathrm{~m} \mathrm{~s}^{-1}$. On either side of the region of maximum winds in the polar cap there is a weakening of the wind. 

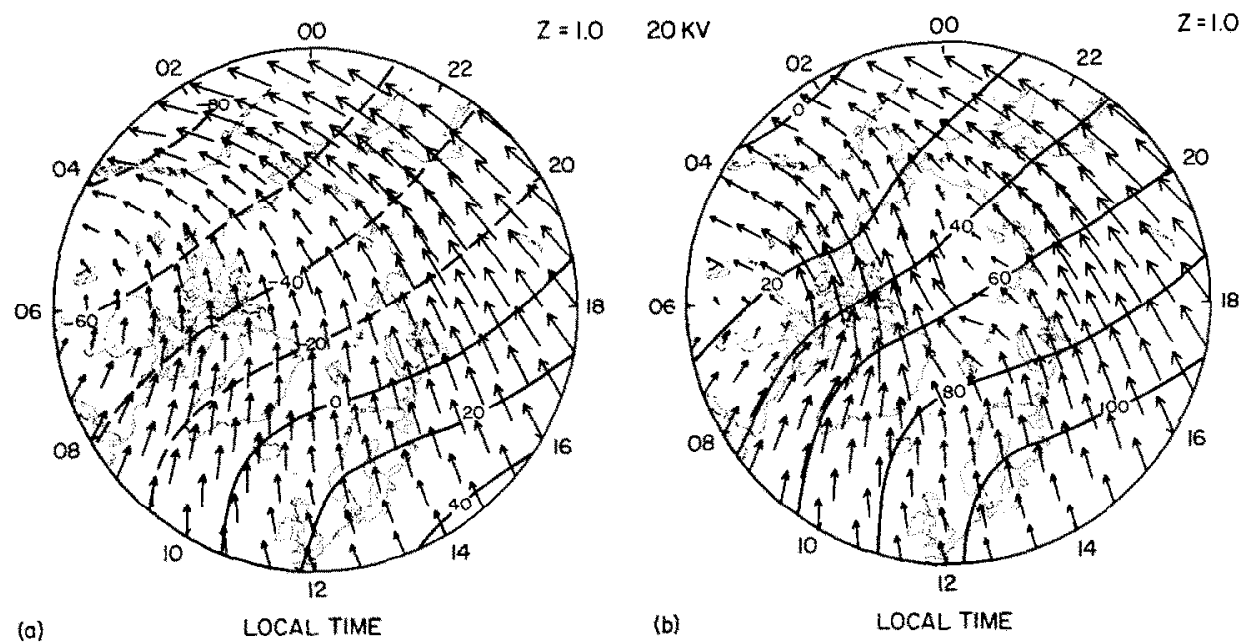

(a)

LOCAL TIME

$z=1,0$

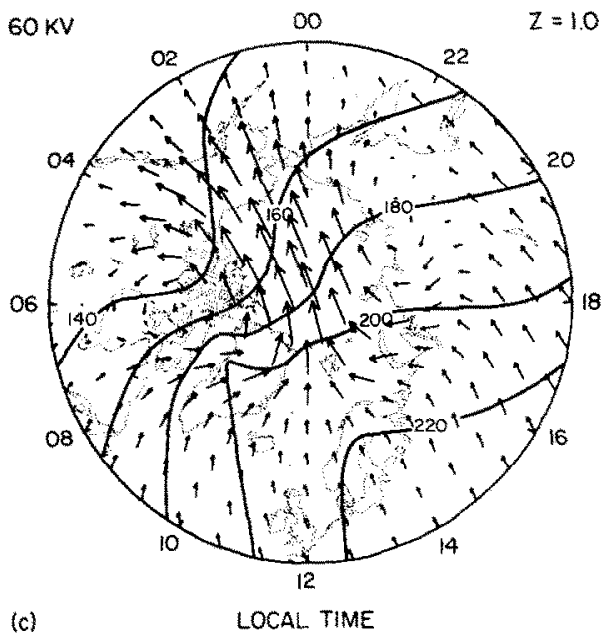

Fig. 4. SAME CAPTION AS IN TIG. 2 EXCEPT For THE NOR THERN HEMISPHERE (WINTER).

The wind speed associated with the maximum arrow is $181 \mathrm{~m} \mathrm{~s}^{-1}$ in (a), $200 \mathrm{~m} \mathrm{~s}^{-1}$ in (b) and $339 \mathrm{~ms}^{-1}$ in (c), respectively.

When the cross-tail potential is increased to $60 \mathrm{kV}$ (Fig. 4c), the winds over the pole increase from 200 to $339 \mathrm{~m} \mathrm{~s}^{-1}$. A surge in the wind from the pole occurs near 02.00 L.T. With the $60 \mathrm{kV}$ cross-tail potential the neutral wind tends to follow the two-cell pattern of magnetospheric convection. The coupling between the neutral winds and ion drift is not as tight in the winter hemisphere as in the sunlit summer hemisphere because of the smaller electron densities. The Joule heating rate in the winter hemisphere for the $60 \mathrm{kV}$ case is only $2 \times 10^{10} \mathrm{~W}$ and there is a calculated temperature increase of about $200 \mathrm{~K}$ from the solar-heating-alone case. There is still a temperature contrast across the winter pole, decreasing from 14.00 L.T. to 02.00
L.T, in contrast to the high-temperature region centered over the summer pole seen in Fig. $2 \mathrm{c}$.

The calculated temperature structure and circulation in the winter lower thermosphere for the same three cases are shown in Fig. 5 . In each of the three cases the temperature uniformly decreases from the $50^{\circ}$ latitude circle to a cold core near the pole and the corresponding low-pressure region drives a counterclockwise circulation throughout the entire highlatitude winter hemisphere. The maximum wind speed increases only from 108 to $117 \mathrm{~m} \mathrm{~s}^{-1}$ and then to $120 \mathrm{~m}$ $\mathrm{s}^{-1}$ as the cross-tail potential increases from 0 to 20 to $60 \mathrm{kV}$. The circumpolar circulation is not influenced directly by the ion drag momentum source because of 

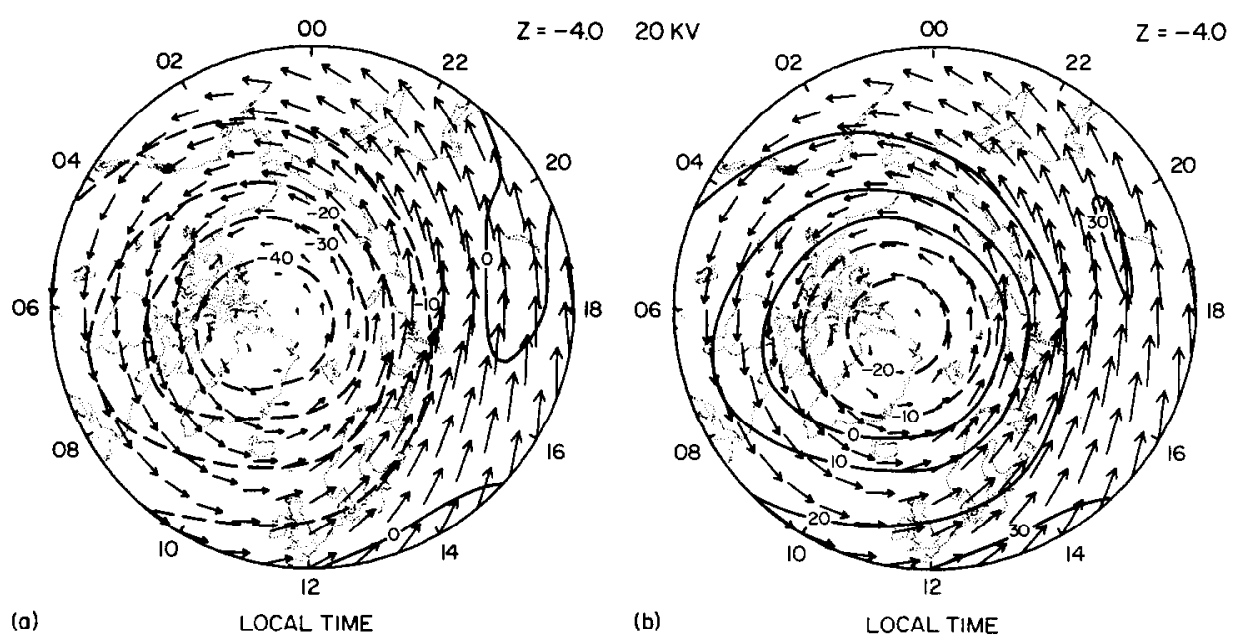

(o)

LOCAL TIME

(b)

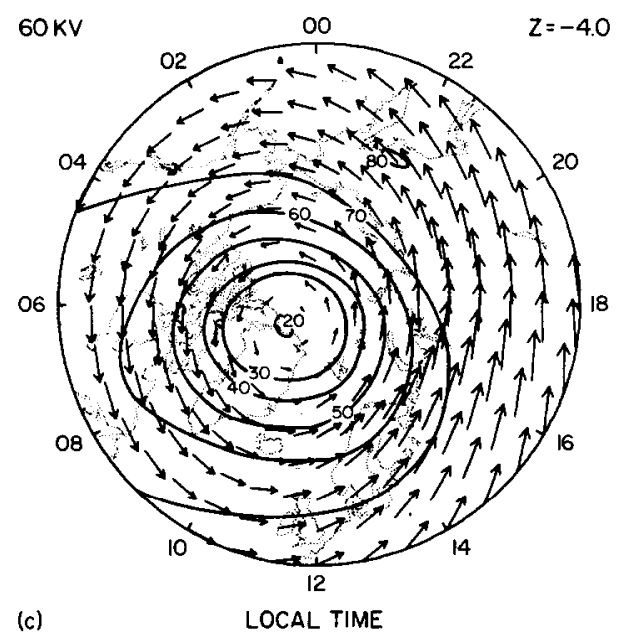

Fig. 5. SAME CAPTION AS IN FIG. 2 EXCEPT ALONG THE $Z=-4(130 \mathrm{~km})$ CONSTANT-PRESSURE SURFACE IN THE NOR THFR N HFMisPHFRF (WINTFR)

The wind speed associated with the maximum arrow is $108 \mathrm{~m} \mathrm{~s}^{-1}$ in (a), $117 \mathrm{~m} \mathrm{~s}^{-1}$ in (b) and $120 \mathrm{~m} \mathrm{~s}^{-1}$ in (c), respectively.

the small electron densities in the winter hemispheric lower thermosphere, as specified by the empirical model of Chiu (1975) and shown in Fig. 1c. Joule heating, primarily from higher levels, raises the overall temperature of the winter polar cap by about $20 \mathrm{~K}$ at this level for the $20 \mathrm{kV}$ cross-tail potential case, as shown in Fig. $5 \mathrm{~b}$, and by another $40 \mathrm{~K}$ at $60 \mathrm{kV}$ (Fig. $5 \mathrm{c}$ ). Thus, over the winter pole the primary effect of the magnetospheric convection on the model lower thermosphere is to raise the overall temperature of the polar cap and slightly increase the wind speed in the winter hemisphere circumpolar vortex.

Cylindrical equidistant projections of global circulation patterns and temperature structures are shown in Figs. 6 and 7 for the upper and lower thermosphere, respectively. For the case of solar heating alone (Fig. 6a), the maximum temperature along the $Z=+1$ constant-pressure surface $(300 \mathrm{~km})$ occurs in the summer polar region and the minimum temperature occurs near $40^{\circ}$ latitude in the winter hemisphere at about 02.00 L.T. The circulation is generally from the subsolar point to the antisolar point, with maximum winds occurring at night.

The circulation and temperature structure is altered primarily at high latitudes by the Joule heating and ion drag momentum sources associated with magnetospheric convection. For a cross-tail potential of $20 \mathrm{kV}$ (Fig. 6b) the overall temperature is increased by about 

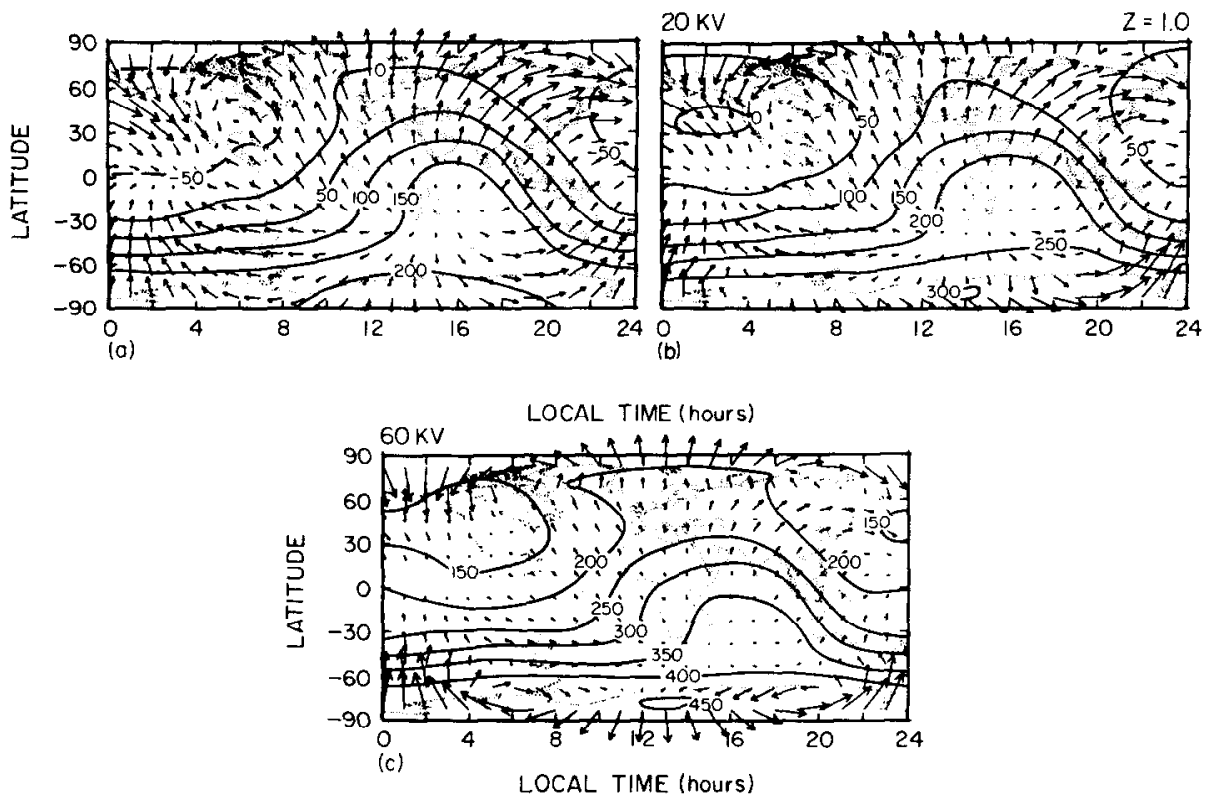

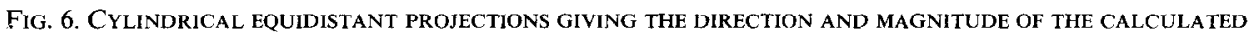
CIRCULATION AND CONTOURS OF PERTURBATION TEMPERATURE (K) ALONG THE $Z=+1(300 \mathrm{~km})$ CONSTANTPRESSURE SURFACE FOR DECEMBER SOLSTICE FOR (a) SOLAR HEATING ONLY, (b) SOLAR HEATING PLUS MAGNETOSPHERIC CONVECTION WITH A CROSS-TAIL POTENTIAL OF $20 \mathrm{kV}$ AND (c) SOLAR HEATING PLUS MAGNETOSPHERIC CONVECTION WITH A CROSS-TAIL POTENTIAL OF $60 \mathrm{kV}$.

The wind speed associated with the maximum arrow is $181 \mathrm{~m} \mathrm{~s}^{-1}$ in (a), $200 \mathrm{~m} \mathrm{~s}^{-1}$ in (b) and $380 \mathrm{~m} \mathrm{~s}^{-1}$ in (c).
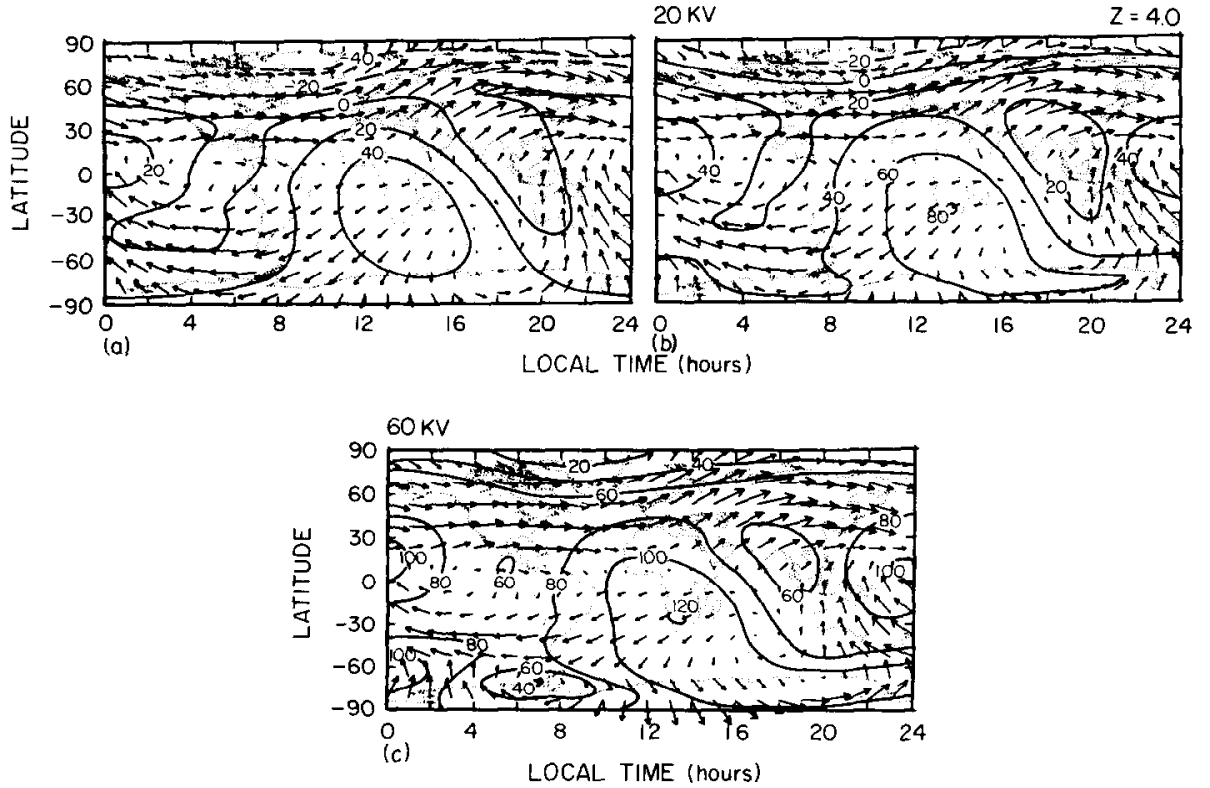

Fig. 7. Same CaPtion as in Fig. 6 EXCEPT AlONG The $Z=-4(130 \mathrm{~km})$ CONSTANT-PRESSURE SURFACE. The wind speed associated with the maximum arrow is $108 \mathrm{~m} \mathrm{~s}^{-1}$ in (a), $117 \mathrm{~m} \mathrm{~s}^{-1}$ in (b) and $120 \mathrm{~m} \mathrm{~s}^{-1}$ in (c). 
$50 \mathrm{~K}$ at $300 \mathrm{~km}$. For a cross-tail potential of $60 \mathrm{kV}$ (Fig. 6c) the high-latitude changes in circulation and temperature structure are much more pronounced. Furthermore, some changes in the temperature and circulation patterns are seen at lower latitudes. The global temperature increase at $300 \mathrm{~km}$ is about $100 \mathrm{~K}$. The high-latitude energy input is redistributed globally by the thermospheric wind system. The maximum winds occur at high latitudes near local midnight and are equatorward at about $400 \mathrm{~m} \mathrm{~s}^{-1}$.

Magnetospheric convection does not greatly change the circulation in the lower thermosphere along the $Z$ $=-4$ constant-pressure surface, as shown in Fig. 7 for the three cases. The exception is at high latitudes in the summer hemisphere for the $60 \mathrm{kV}$ cross-tail potential case, as discussed previously. The main effect of magnetospheric convection in the lower thermosphere is to increase the global temperature. The perturbation temperature increases globally by about $20 \mathrm{~K}$ from the solar-heating-only case to the case when magnetospheric convection with the $20 \mathrm{kV}$ cross-tail potential is included. The overall temperature increase is another $40 \mathrm{~K}$ when the cross-tail potential is increased from 20 to $60 \mathrm{kV}$.

In Fig. 8, latitudinal slices of the 12.00 L.T. perturbation temperature and meridional wind are contoured, respectively for the solar-heating-only case (a and $c$ ) and for the case with solar heating plus $60 \mathrm{kV}$ cross-tail potential ( $b$ and $d$ ). The geographic and geomagnetic poles are assumed to be coincident. The perturbation temperature for the solar-heating-only case, shown in Fig. 8a, is greater in the summer hemisphere than in the winter hemisphere. The summer-to-winter pole temperature difference is about $200 \mathrm{~K}$ in the upper thermosphere and $100 \mathrm{~K}$ in the lower thermosphere. When magnetospheric convection with a cross-tail potential is included, the overall temperature of the thermosphere increases as shown in Fig. 8 b. The perturbation temperature at $F$-region heights increases by $250 \mathrm{~K}$ over the summer pole and by $200 \mathrm{~K}$ over the winter pole. The temperature in the lower thermosphere is relatively uniform except for the cold temperatures at high latitudes in the winter hemisphere. The vertical temperature gradient in the
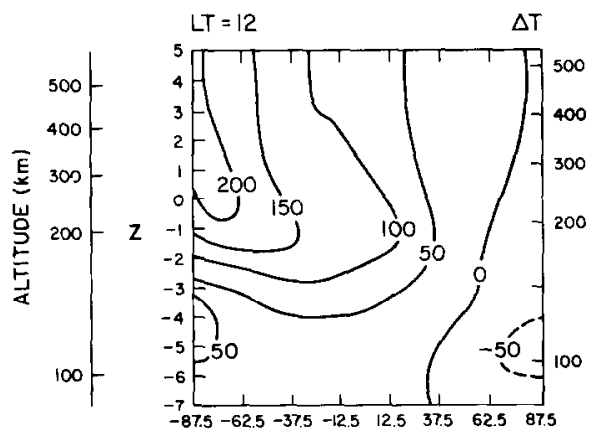

LATITUDE

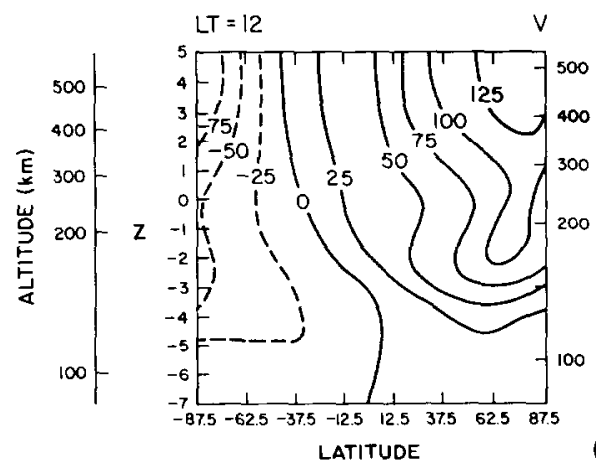

LATITUDE

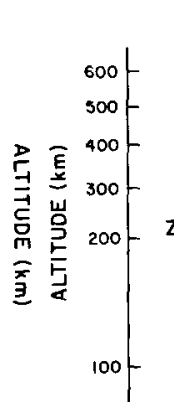

(a)

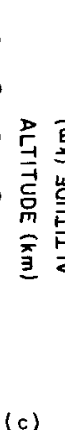

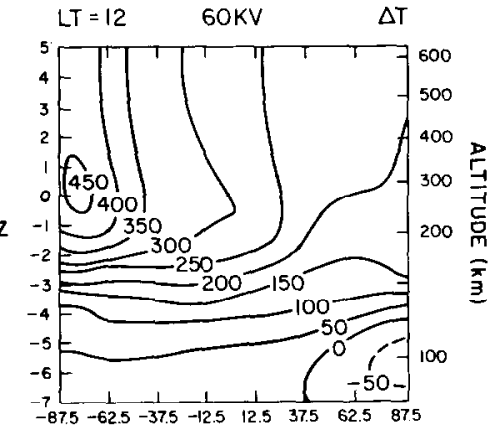

LATITUDE

(b)

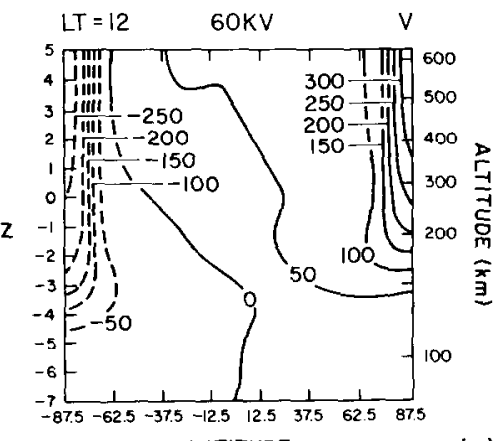

(d)

Fig. 8. MERIDIONAL Cross SECTIONS GIVING CONTOURS OF THE CALCUlated PERTURBATION TEMPERATURE (K)

[(a) AND (b)] AND MERIDIONAL WIND SPEED ( $\mathrm{m} \mathrm{s}^{-1}$, POSITIVE NORTHWARD) [(c) AND (d)], RESPECTIVELY.

The local time of the meridional slice is 12.00 L.T. (a) and (c) are the perturbation temperaturc and meridional wind for the case of solar heating only, and (b) and (d) are the perturbation temperature and meridional wind for the case of solar heating plus magnetospheric convection with a cross-tail potential of $60 \mathrm{kV}$. 
lower thermosphere drives a downward transport of heat by molecular diffusion from the upper to the lower thermosphere and this transport is considerably enhanced with strong magnetospheric convection. Although the energy input due to magnetospheric convection occurs at high latitudes, the energy is redistributed globally by the wind system and is ultimately transported as mentioned above to the lower thermosphere, by thermal conduction to be balanced by thermal infrared radiative cooling by optically active minor neutral constituents (e.g., $\mathrm{CO}_{2}$ and $\mathrm{NO}$ ).

The calculated meridional winds at $12.00 \mathrm{~L}$.T. for the two cases are contoured in Figs. 8c and 8d respectively. For the solar-heating-only case the winds are poleward from approximately the subsolar point, i.e., $23.5^{\circ} \mathrm{S}$ for December solstice. Maximum noontime meridional winds occur in the upper thermosphere, with velocities of $75 \mathrm{~m} \mathrm{~s}^{-1}$ over the summer pole and $125 \mathrm{~m} \mathrm{~s}^{-1}$ over the winter pole. Magnetospheric convection greatly increases the cross-polar winds at high latitudes. The winds increase from 75 to $250 \mathrm{~m} \mathrm{~s}^{-1}$ over the summer pole and from 125 to $300 \mathrm{~m} \mathrm{~s}^{-1}$ over the winter pole. Because of the greater $E$ - and $F_{1}$-region electron and ion densities in the summer hemisphere, the ion drag momentum source effectively accelerates the wind to a lower altitude in the summer hemisphere $(Z=-4$, i.e., about $130 \mathrm{~km})$ than in the winter hemisphere $(Z=-2$, i.e., about $180 \mathrm{~km}$ ).

A similar latitudinal slice, but along the 00.00 L.T. meridian, is shown in Fig. 9. For both cases the maximum temperature occurs over the summer pole but the temperature is about $200 \mathrm{~K}$ larger when magnetospheric convection is included in the calculation. The minimum temperatures in the upper thermosphere occur in midlatitudes of the winter hemisphere for both cases.

The meridional winds along the 00.00 L.T. meridian are shown in Figs. $9 \mathrm{c}$ and $9 \mathrm{~d}$ for the two cases. When magnetospheric convection is included the equatorward transport along the midnight meridian is greatly enhanced from the meridional winds calculated in the solar-heating-only case. The equatorward winds increase from about 100 to $400 \mathrm{~m} \mathrm{~s}^{-1}$ over the summer pole and from 100 to $300 \mathrm{~m} \mathrm{~s}^{-1}$ over the winter pole. There is a sharp gradient in the meridional winds near $60^{\circ}$ latitude in both hemispheres, indicating the equatorward limit of the magnetospheric convection forcing at this local time.
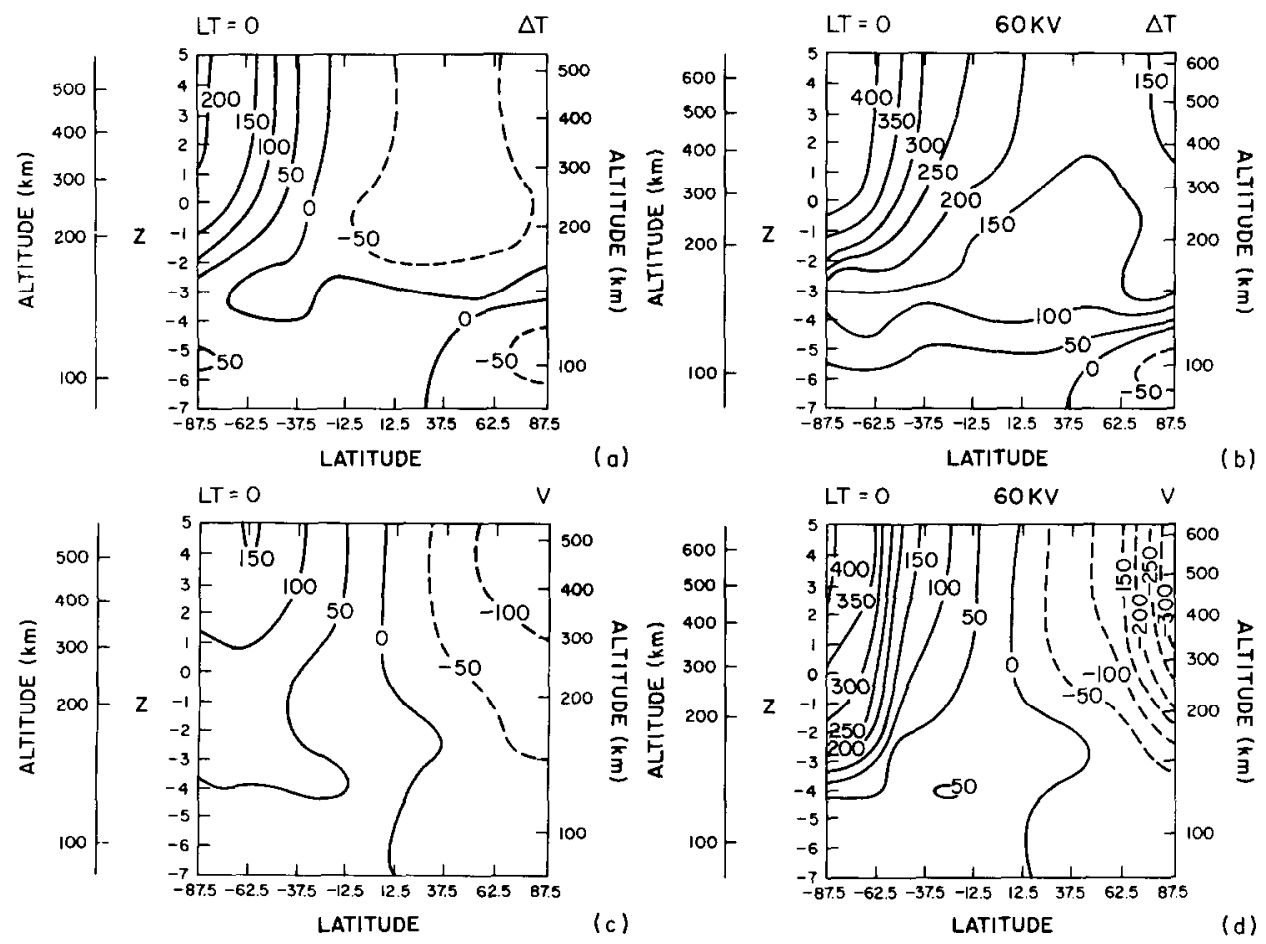

Fig. 9. SAME CAPtion as Fig. 8 except along the 00.00 L.T. MERIDion. 


\section{LINEARITY OF THE SOLUTION}

An important question in analyzing thermospheric dynamic data and formulating simple dynamic models is whether the solar-driven and high-latitude auroraldriven circulations and temperature structures can be linearly combined to derive the total structure. If a linear combination were to closely approximate the total circulation and temperature structure, then it would be possible to analyze high-latitude plasma dynamic interactions with the neutral gas independently and to superimpose linearly the results upon a solar-driven circulation and temperature pattern. This would simplify the analysis of thermospheric dynamics data obtained by Dynamics Explorer satellites that are investigating magnetospheric-ionospheric-thermospheric coupling processes at high latitudes. Furthermore, more confidence could be placed in linear perturbation model approaches to describing thermospheric dynamics.

To determine the extent to which a linear superposition of solutions applies we performed several numerical experiments with the TGCM. The base case is the TGCM run that includes both solar heating and magnetospheric convection with a cross-tail potential of $60 \mathrm{kV}$ and with coincident poles, as was discussed in the previous sections. Two other TGCM runs were used for comparison. The first is the case for solar heating only, also presented in the previous sections and the second is for magnetospheric convection with a cross-tail potential of $60 \mathrm{kV}$ alone. These two solutions are linearly combined and then subtracted from the base case to determine the difference fields for winds and temperatures. The difference fields thus represent departures from true linearity of the solar and magnetospheric convection solutions from the combined solution.

The results for both the base case and solar-heatingonly case have been discussed in the previous sections. For the case of magnetospheric convection alone the temperature structure and circulation over the summer pole on the $Z=+1$ constant-pressure surface is shown in Fig. 10a. The circulation follows the two-cell pattern of magnetospheric convection closely, with a maximum wind speed of $336 \mathrm{~m} \mathrm{~s}^{-1}$ over the pole. The calculated perturbation temperature has a maximum value of about $260 \mathrm{~K}$ near the pole and decreases equatorward. When this magnetospheric-convection-only solution is added to the solar-heating-only solution shown in Fig. $2 a$ and then subtracted from the base case shown in Fig. 2 c, the difference fields shown in Fig. 10 b remain. The difference temperature is smallest over the summer pole, $6 \mathrm{~K}$, increasing equatorward to about $60 \mathrm{~K}$ at $50^{\circ} \mathrm{S}$ latitude. The circulation difference is relatively small compared to the combined fields. The maximum wind difference is $40 \mathrm{~m} \mathrm{~s}^{-1} \mathrm{compared}$ to the $380 \mathrm{~m} \mathrm{~s}^{-1}$ in the base case. Thus, to within about $10 \%$ the linear combination of solutions represents the total circulation field. The difference circulation is mainly equatorward, indicating that the solar-driven component has an advective transport of heat from high to low latitudes.

The calculated magnetospheric convection-driven wind system along the $Z=-4$ constant-pressure surface $(130 \mathrm{~km})$ in the summer lower thermosphere is shown in Fig. 10c. The circulation has the two-cell pattern of magnetospheric convection; however, it lags the $\mathbf{E} \times \mathbf{B}$ ion drift pattern by about $4 \mathrm{~h}$. The circulation is counterclockwise around the warm high-pressure region on the $20.00 \mathrm{~L}$.T. side of the polar cap and is clockwise around the cold low-pressure region on the $08.00 \mathrm{~L}$.T. side. The maximum wind speed is about $50 \mathrm{~m}$ $\mathrm{s}^{-1}$. When this solution is added to the solar-driven circulation shown in Fig. 3a and subtracted from the base case shown in Fig. 3c, the difference field shown in Fig. 10d results. The nonlinearity of solutions produces a cold low-pressure region with a clock wise circulation over the summer pole. The maximum wind around the cold low-pressure region is about $60 \mathrm{~m} \mathrm{~s}^{-1}$ and since this is comparable to the total wind speed of $89 \mathrm{~m} \mathrm{~s}^{-1}$ the analysis indicates that a linear superposition of solutions is not very accurate in the lower thermosphere.

In the winter polar region the electron densities are lower and the ion drag momentum source is weaker, resulting in a more complex circulation pattern and temperature structure. The magnetosphericconvection-only circulation and temperature structure on the $Z=+1(300 \mathrm{~km})$ constant-pressure surface is shown in Fig. 11a. The maximum perturbation temperature of $90 \mathrm{~K}$ occurs over the winter pole and decreases to about $50 \mathrm{~K}$ near $10.00 \mathrm{~L}$.T. and to about $60 \mathrm{~K}$ near $20.00 \mathrm{~L} . \mathrm{T}$. around the $50^{\circ} \mathrm{N}$ latitude circle. Thus, Joule heating results in a significant temperature increase of about $120 \mathrm{~K}$ at $F$-region heights in the winter polar region. The circulation follows the two-cell convection pattern but it lags the ion drift pattern by about $2 \mathrm{~h}$. This is in contrast to the summer polar region where there was a much smaller lag between the circulation and ion drift pattern due to the higher electron densities and corresponding larger ion drag momentum source in the summer hemisphere. It is also seen in Fig. 11a that the sunward circulation at auroral zone latitudes is stronger on the evening side of the polar cap than on the morning side, again due to larger electron densities in the evening than during the early morning hours. When this solution is added to the 
$Z=1.0$
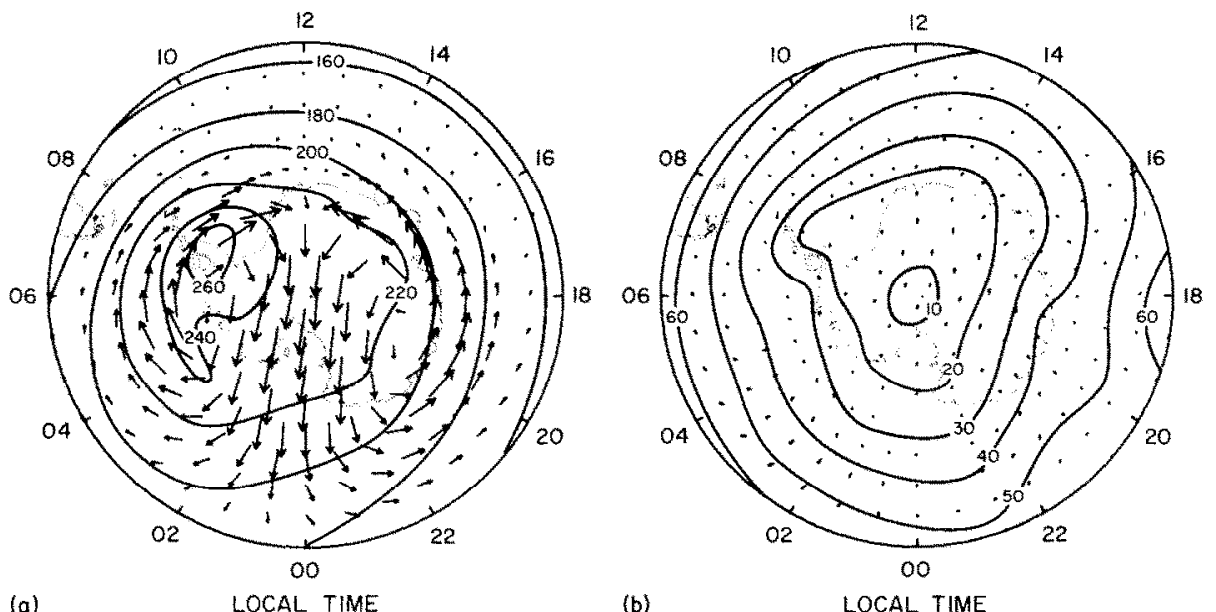

(a)

LOCAL TIME

$$
Z=-4.0
$$
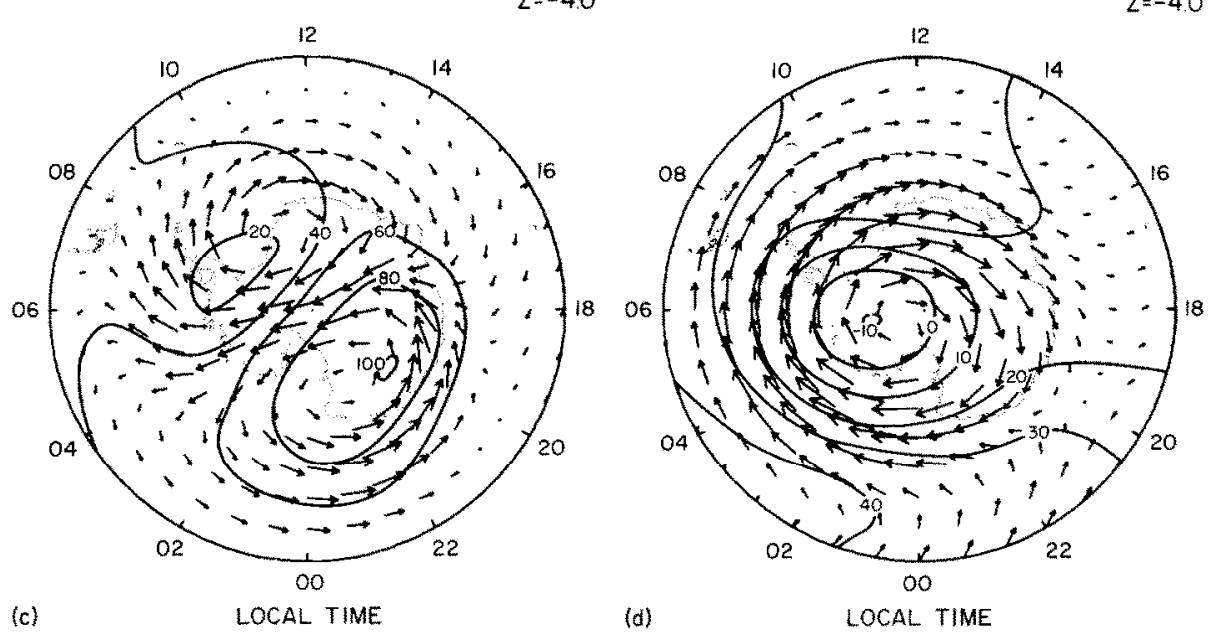

Fig. I0. POLAR plots GIVING THE DIRECTION ANU MaGNTUdE OF THE CALCULATEd SOUTHERN HEMISPHERE (SUMMER) HGH LATITUDE CIRCULATION AND CONTOURS OF PERTURBATION TEMPERATURE (K) FOR THE CASE OF MAGNETOSPHERIC CONVECTION WITH A CROSS-TAIL POTENTIAL OF $60 \mathrm{kV}$ ALONE: (a) $Z=+1$ CONSTANT-PRESSURE SURFACE $(300 \mathrm{~km})$, (c) $Z=-4$ CONSTANT-PRESSURE SURFACE $(130 \mathrm{~km})$.

The linearity difference solutions between the combined and superimposed solar and magnetospheric convection cases are: (b) along the $Z=+1$ and (d) along the $Z=-1$ constant-pressure surfaces. The maximum arrow in (a) represents a wind velocity of $380 \mathrm{~m} \mathrm{~s}^{-1}$; the arrows in (b) are drawn relative to (a) for ease in comparison and the maximum arrow represents $40 \mathrm{~m} \mathrm{~s}^{-1}$. The maximum arrow in (c) is $89 \mathrm{~m} \mathrm{~s}^{-1}$; the arrows in (d) are drawn relative to (c) and the maximum arrow represents $60 \mathrm{~m} \mathrm{~s}^{-1}$.

solar-driven-only solution shown in Fig. $4 \mathrm{a}$ and then subtracted from the base case shown in Fig. 4c, the difference field shown in Fig. $11 \mathrm{~b}$ is derived. The difference circulation has a two-cell pattern with a direction opposite that of the ion drift of magnetospheric convection. The maximum wind speed difference of $60 \mathrm{~m} \mathrm{~s}^{-1}$ is about $18 \%$ of the maximum wind speed of $340 \mathrm{~m} \mathrm{~s}^{-1}$ in the base case. The temperature difference between the base case and the linear superposition is about $150 \mathrm{~K}$ in the winter polar region. Some of this temperature difference may be due to non-linear advective transport of energy to the winter polar region. However, it appears that most of it is due to nonlinearity of the Joule heating, i.e., the Joule heating is proportional to the square of the difference between neutral and ion velocities. In summary, at $F$-region heights a linear superposition gives the circulation pattern to within $20 \%$, but there is a large difference in the temperature pattern.

The magnetospheric-convection-only circulation 


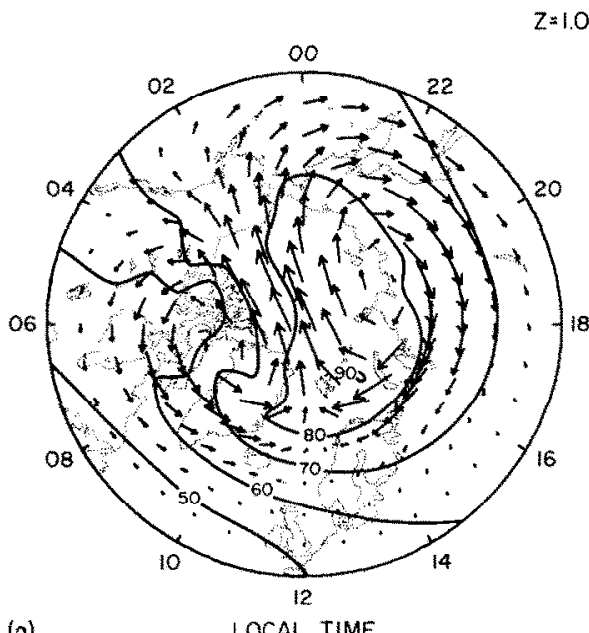

$Z=1.0$

(o)

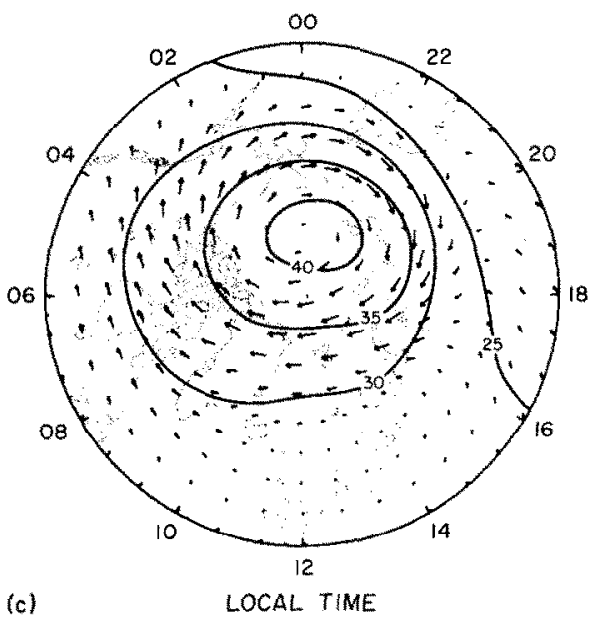

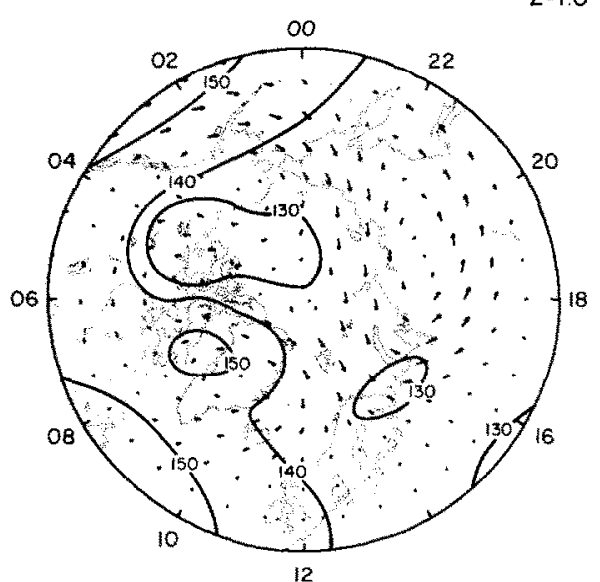

(b) LOCAL TIME

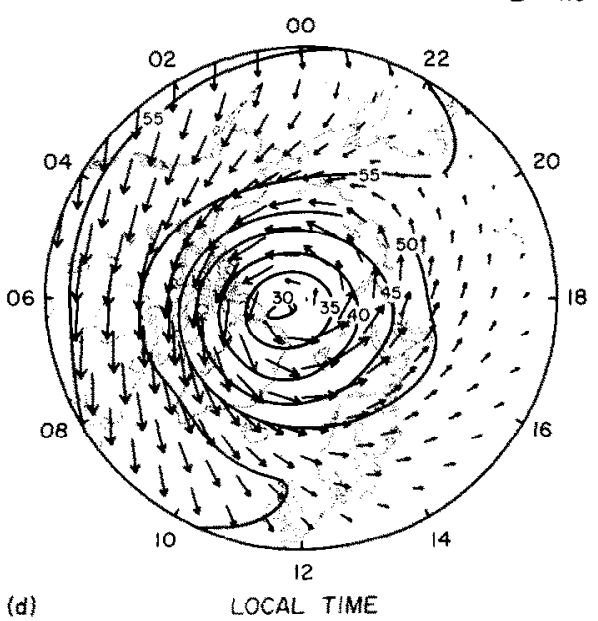

$Z=-4.0$

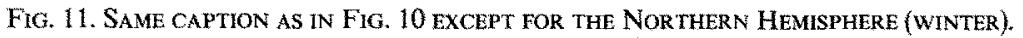

The maximum arrow in (a) represents a wind velocity of $245 \mathrm{~m} \mathrm{~s}^{-1}$ and the arrow in (b) is drawn relative to (a), with the maximum arrow representing $60 \mathrm{~m} \mathrm{~s}^{-1}$. The maximum arrow in (c) is $9 \mathrm{~m} \mathrm{~s}^{-1}$ and the arrows in (d) are drawn relative to that in (c) with the maximum arrow representing $22 \mathrm{~m} \mathrm{~s}^{-1}$.

and temperature structure along the $Z=-4$ constantpressure surface $(130 \mathrm{~km})$ in the lower thermosphere, is shown in Fig. $11 \mathrm{c}$. The main feature is that Joule heating generates a warm high-pressure region over the pole, with a clockwise circulation around the region and a maximum wind speed of $9 \mathrm{~m} \mathrm{~s}^{-1}$. The ion drag momentum source in the winter hemisphere does not alter the wind pattern into a 06.00 U.T. -18.00 U.T. temperature contrast as it does in the summer hemisphere because of the low winter hemisphere electron densities. Although the empirical electron density model does not include an auroral zone enhancement of electron density in the $E$-region, it is most likely, in reality, that some such enhancement by auroral particle precipitation is occurring at all times and should be included in the model calculation. The ionization used here therefore represents a lower limit to winter auroral ionization.

The magnetospheric-convection-only solution is added to the solar-heating-only solution shown in Fig. $5 \mathrm{a}$ and then subtracted from the base case shown in Fig. $5 \mathrm{c}$. The resulting difference solution, shown in Fig. 11d, indicates a relatively weak cold low-pressure region near the pole, with a counterclockwise circulation about the pole and with a maximum wind speed difference of $22 \mathrm{~m} \mathrm{~s}^{-1}$. This difference circulation pattern is similar to but weaker than the pattern that occurred over the summer pole. 
In conclusion, it appears that the solar-driven and magnetospheric convection-driven solutions add linearly to the joint solution to within $10-20 \%$ at $F$ region heights, where the motion is mainly controlled by the ion drag momentum source. In the lower thermosphere there are considerable differences from linear superposition. The temperature structure obtained by linear superposition also shows significant departures from the total temperature field of the base case, apparently due to the non-linear nature of transport of energy by the winds and of the Joule heating which depends on the square of the difference between neutral and ion velocities.

\section{F-REGION WINDS OBSERVED BY THE DYNAMICS EXPLORER SATELLITE}

The Dynamics Explorer satellite (DE-2) launched in August 1981 carried Fabry-Perot Interferometer(FPI) and Wind and Temperature Spectrometer (WATS) instruments to provide measurements of the neutral winds and temperature. The FPI measures winds and temperature by detecting shifts of the line position and the Doppler width of various airglow emissions, while the WATS determines winds and temperature from atmospheric gas particle kinetics. Because of differing measurement techniques employed by the two instruments, the orientation of the spacecraft and the polar orbit, the FPI measures the meridional component of the wind ahead of the spacecraft (Hays et al., 1981) while the WATS measures the zonal component of the wind at the spacecraft (Spencer et al., 1981, 1982). These two components are appropriately summed vectorially to provide the thermospheric wind along the spacecraft path, as discussed by Killeen et al. $(1982,1983)$. Four wind vector determinations over the summer pole, during the period 21 October to 24 October 1981, are shown in Fig. 12a. Even though these measurements are obtained during late October they are representative of summer conditions. Roble et al. (1977) have shown that a solstice-type circulation is rapidly established in about a week after equinox with
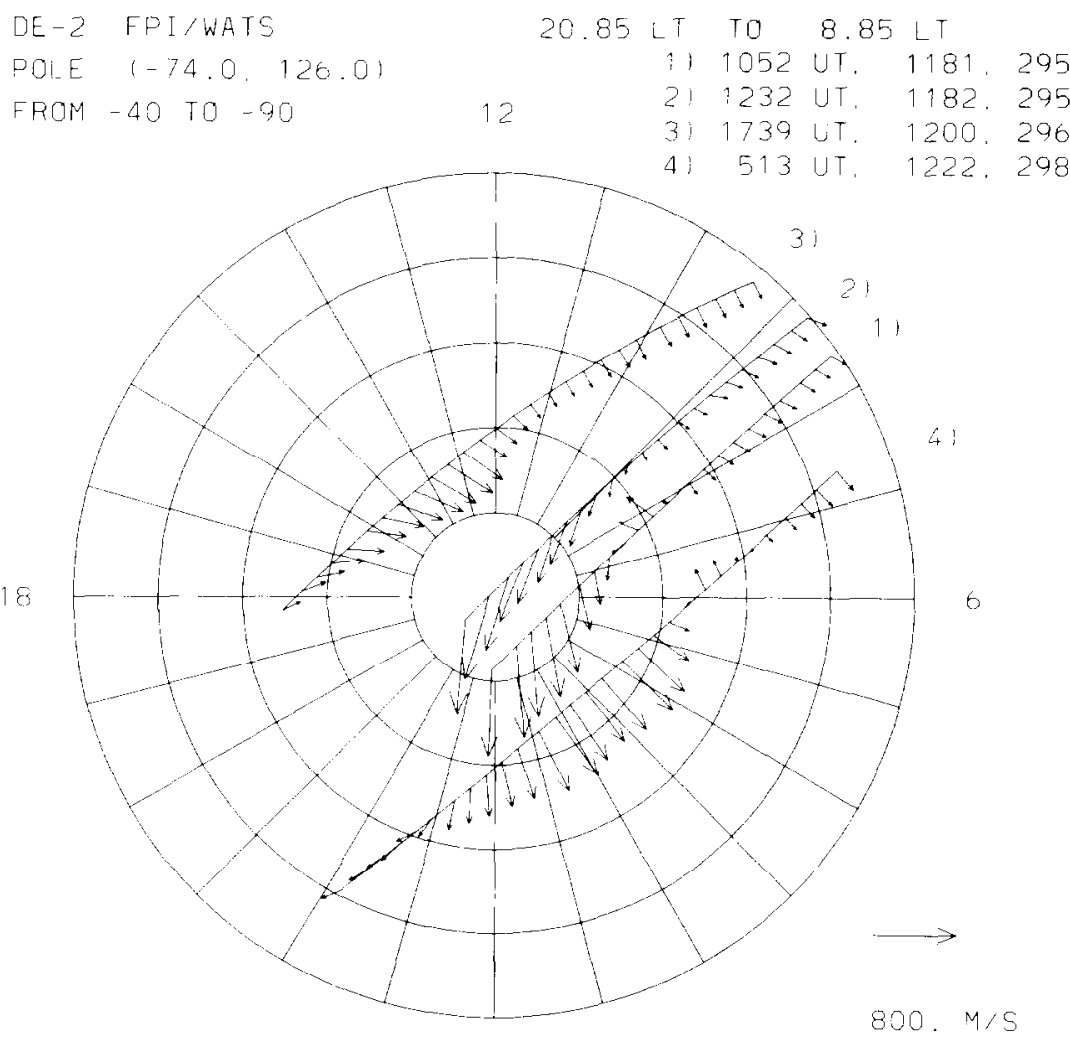

(a) 


\begin{tabular}{|c|c|c|c|c|c|c|}
\hline$D E-2$ & FPI/WATS & & $6.02 \mathrm{LT}$ & TO & 18.02 & $L T$ \\
\hline POLE & $(80.0 .282 .0)$ & & 11 & 1929 & $\cup T$ & 1810 \\
\hline ROM & 40 TO 90 & 12 & 2) & $\begin{array}{r}2243 \\
332\end{array}$ & $\begin{array}{l}U T . \\
U T .\end{array}$ & $\begin{array}{l}1813 . \\
1816 .\end{array}$ \\
\hline
\end{tabular}

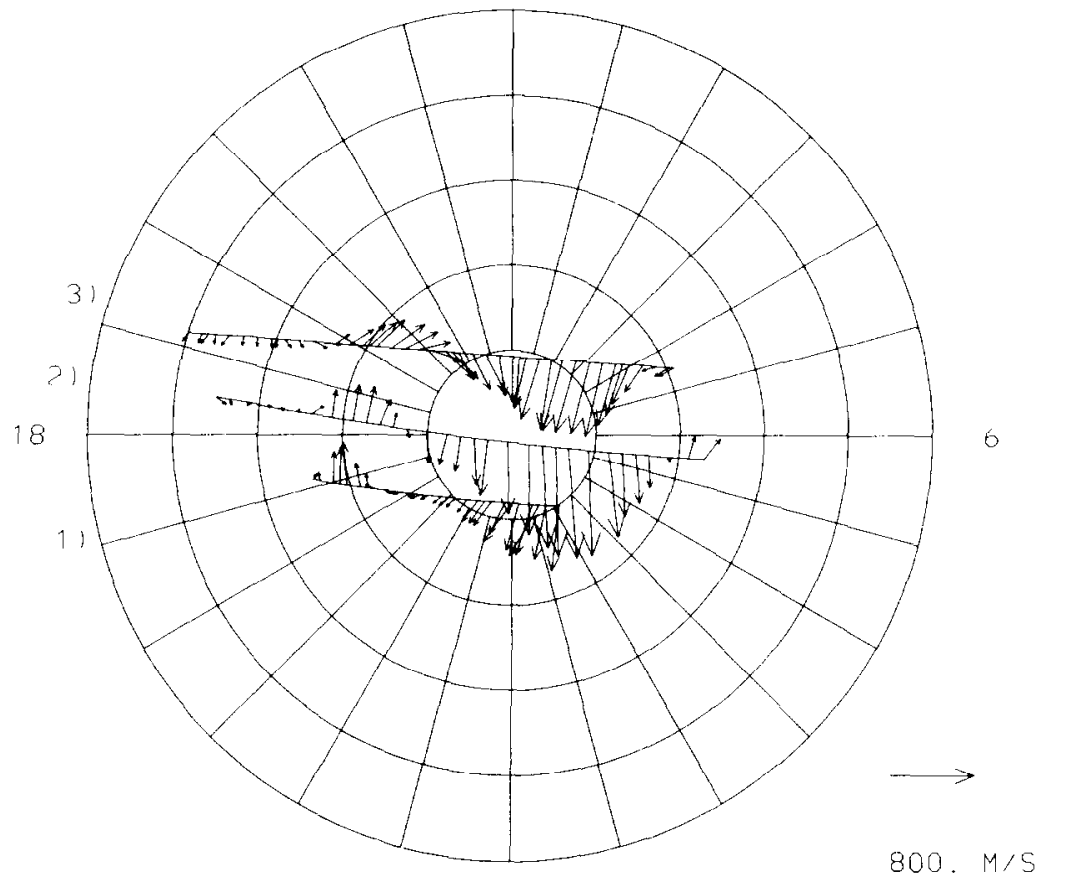

(b)

() HRS

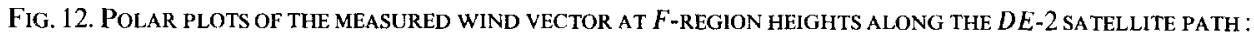
(a) WINDS ON FOUR ORBITS MEASURED OVER THE SOUTHERN MAGNETIC POLAR CAPON 22-23 OCTOBER 1981 AND(b) WINDS MEASURED ON THREE ORBITS OVER THE NORTHERN MAGNETIC POLAR CAP ON 3 - DECEMBER 1981.

some further intensifications of the circulation as solstice is approached. Since the $D E-2$ satellite perigee was over the Southern (summer) Hemisphere in late October, we consider the wind measurements as representative of solstice conditions. As discussed by Killeen et al. $(1982,1983)$, the wind vectors are shown in geomagnetic coordinates because of the control of the auroral $F$-region winds by ion drag. The $F$-region winds over the summer pole are strongly controlled by magnetospheric convection and the characteristic twocell circulation pattern is evident in the data. The maximum wind velocities over the polar cap seen in these data range between $500-750 \mathrm{~m} \mathrm{~s}^{-1}$.

The winds measured over the winter pole during the period 3 December to 4 December 1981 are shown in Fig. 12b. The wind vectors are those obtained during twilight and daytime hours because of the larger airglow signal. The measured wind pattern over the winter polar region is similar to the pattern over the summer hemisphere, indicating a strong ion drag control of $F$-region winds by magnetospheric convection in this hemisphere also. The two-cell circulation pattern again emerges. The measured maximum winds over the winter polar cap range between 500 and $800 \mathrm{~m} \mathrm{~s}^{-1}$ and the sunward winds in the auroral oval are about $300 \mathrm{~m} \mathrm{~s}^{-1}$.

The TGCM has been used to calculate the thermospheric winds and temperatures for conditions near the end of Octoher for comparison with $D E$-2 wind data. The model run includes solar e.u.v. and u.v. heating and magnetospheric convection with a crosstail potential of $60 \mathrm{kV}$. We also assume displaced geomagnetic and geographic poles with the North geomagnetic pole at $79^{\circ} \mathrm{N}, 290^{\circ} \mathrm{E}$ and the South geomagnetic pole at $74.5^{\circ} \mathrm{S}, 127^{\circ} \mathrm{E}$ in accordance with the model of Sojka et al. (1980). The calculated winds at four different universal times are shown in Fig. 13. The wind pattern in the Southern Hemisphere in October is strongly controlled by the ion drag momentum source of magnetospheric convection. It has a geographic variation as the magnetic pole rotates about the geographic pole and a universal time dependence in 


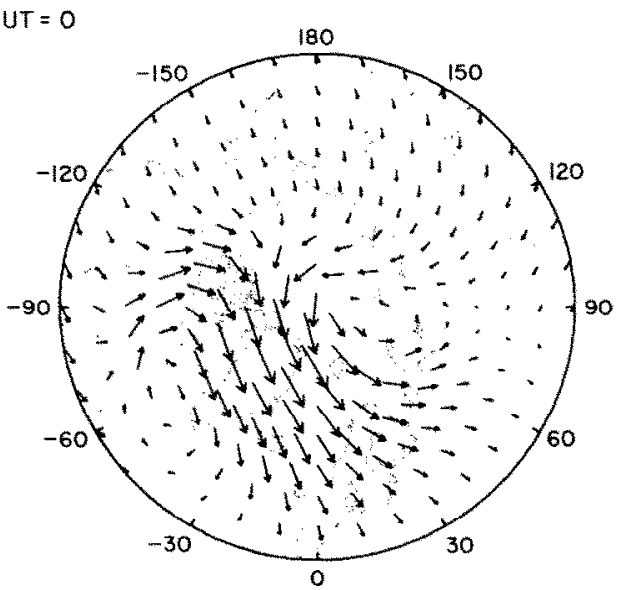

(a)

UT $=12$

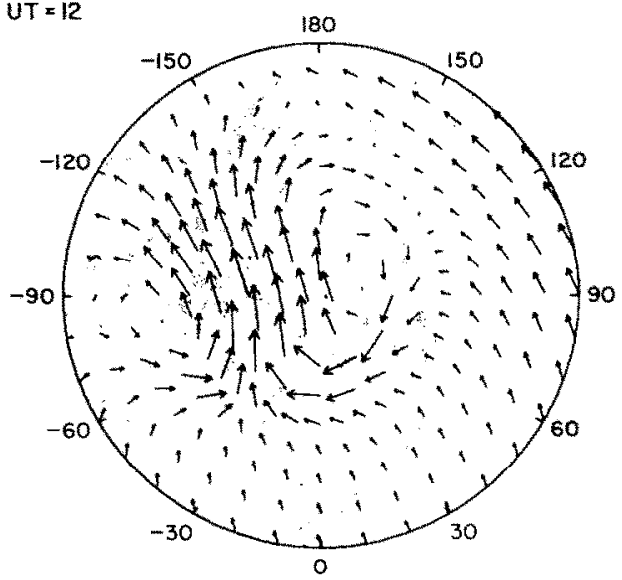

(c)

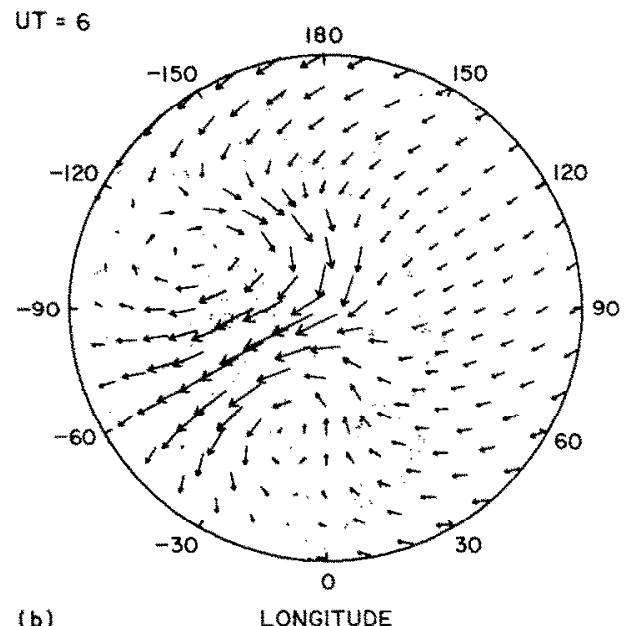

UT $=18$

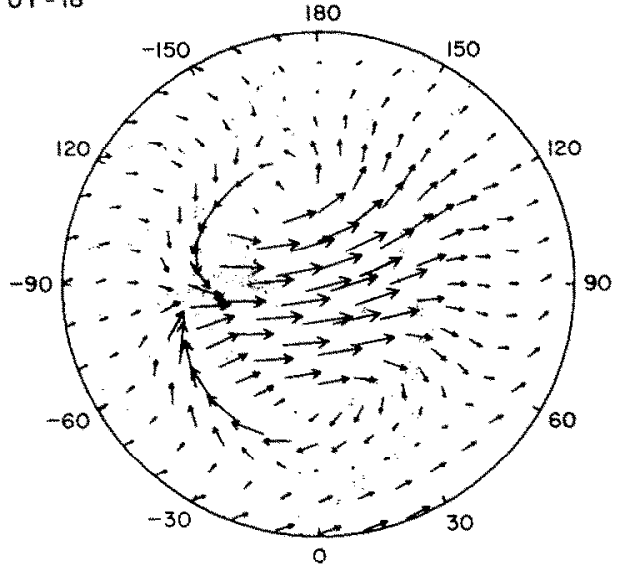

(d)

Fig. 13. Polar plots of the calculated circulation over the SOUthern Hemisphere (SUMmer) polar REGION DURING LATE OCTOBER FOR THE CASE OF SOLAR UEATING PLUS MAGNETOSPHERIC CONVECTION WITH A CROSS-TAIL POTENTIAL OF $60 \mathrm{kV}$.

The geomagnetic and geographic poles are displaced and the circulation at four U.T.s are given (a) 00.00 U.T., (b) 06.00 U.T., (c) 12.00 U.T. and (d) 18.00 U.T. The maximum arrow represents (a) $567 \mathrm{~m} \mathrm{~s}^{-1}$, (b) $415 \mathrm{~m} \mathrm{~s}^{-\frac{1}{3}}$, (c) $391 \mathrm{~m} \mathrm{~s}^{-1}$ and (d) $400 \mathrm{~m} \mathrm{~s}^{-1}$.

part due to the $5^{\circ}$ offset of the magnetospheric convection pattern from the geomagnetic pole and in part due to ion drag variations. A maximum wind of 567 $\mathrm{m} \mathrm{s}^{-1}$ occurs near 00.00 U.T. and a minimum of $391 \mathrm{~m}$ $\mathrm{s}^{-1}$ near 12.00 U.T.

To compare these values with the satellite measurements we follow the satellite trajectory through a three-dimensional grid of TGCM output at a given time and interpolate to find the wind vector along the satellite path. The calculated wind vectors for the $D E-2$ satellite passes over the Southern Hemisphere magnetic polar cap are shown in Fig. 14a and the calculated winds over the Northern Hemisphere magnetic polar cap are shown in Fig. 14b. Comparing these values to the measured values shown in Fig. 12 shows that there is reasonable agreement in direction. The measurements do show considerable variability in direction and speed from pass to pass. The maximum speed of the wind calculated over the polar cap is about $500 \mathrm{~m} \mathrm{~s}^{-1}$, whereas the observed speeds range from 500 to $800 \mathrm{~m} \mathrm{~s}^{-1}$. To obtain better agreement in magnitude it would only be necessary to increase the ion drag acting on the neutral winds. This could be accomplished either by increasing the ion drift velocity of magnetospheric convection or by increasing electron density in the high-latitude polar cap. 
The magnitude of the electron density at $F$-region heights in the winter polar cap has an important influence on the neutral winds at these heights. We present results from two TGCM numerical simulations in Fig. 15 that illustrate the effect of electron densities on the wind and temperature structure of the polar cap. In the first numerical simulation we consider an electron density associated with solar ionization only. Therefore, in the winter polar cap where sunlight is absent, the electron densities are small, owing to a small background production from scattered Lyman- $\beta$ and other lines from the Earth's geocorona. The calculated wind and temperature structure along the $Z=+1$ constant-pressure surface $(300 \mathrm{~km})$ in the winter polar cap for the case of solar heating plus magnetospheric convection with a cross-tail potential of $60 \mathrm{kV}$ is shown in Fig. 15a. For this case with the low background electron densities in the polar cap the winds are similar to the solar-heating-only case shown in Fig. 4a. There is no evidence of a tendency for the winds to follow the magnetospheric convection pattern. When the electron density in the winter polar cap is increased to calculated concentrations comparable to that predicted by the Chiu (1975) empirical electron density model, ion dragdriven winds develop, but lag the magnetospheric convection pattern by $2 \mathrm{~h}$, as shown in Fig. 15b. The maximum polar cap wind speed is $230 \mathrm{~m} \mathrm{~s}^{-1}$ for the low electron density case and $340 \mathrm{~m} \mathrm{~s}^{-1}$ for the high electron density case. Since $D E-2$ measurements show that winds in the winter polar cap apparently follow the magnetospheric convection pattern even more closely, suggesting that the electron density and hence ion drag in the auroral and polar cap is enhanced beyond that inferred from the Chiu model. This suggested enhancement may be due to auroral particle precipitation, especially in the lower thermosphere, and to the convection of $F$-region plasma from sunlit regions (e.g., Sojka et al., 1979).

\section{CONCLUSIONS AND DISCUSSION}

The TGCM calculations for solstice conditions show that the ion drag momentum source associated with magnetospheric convection has a dominant influence
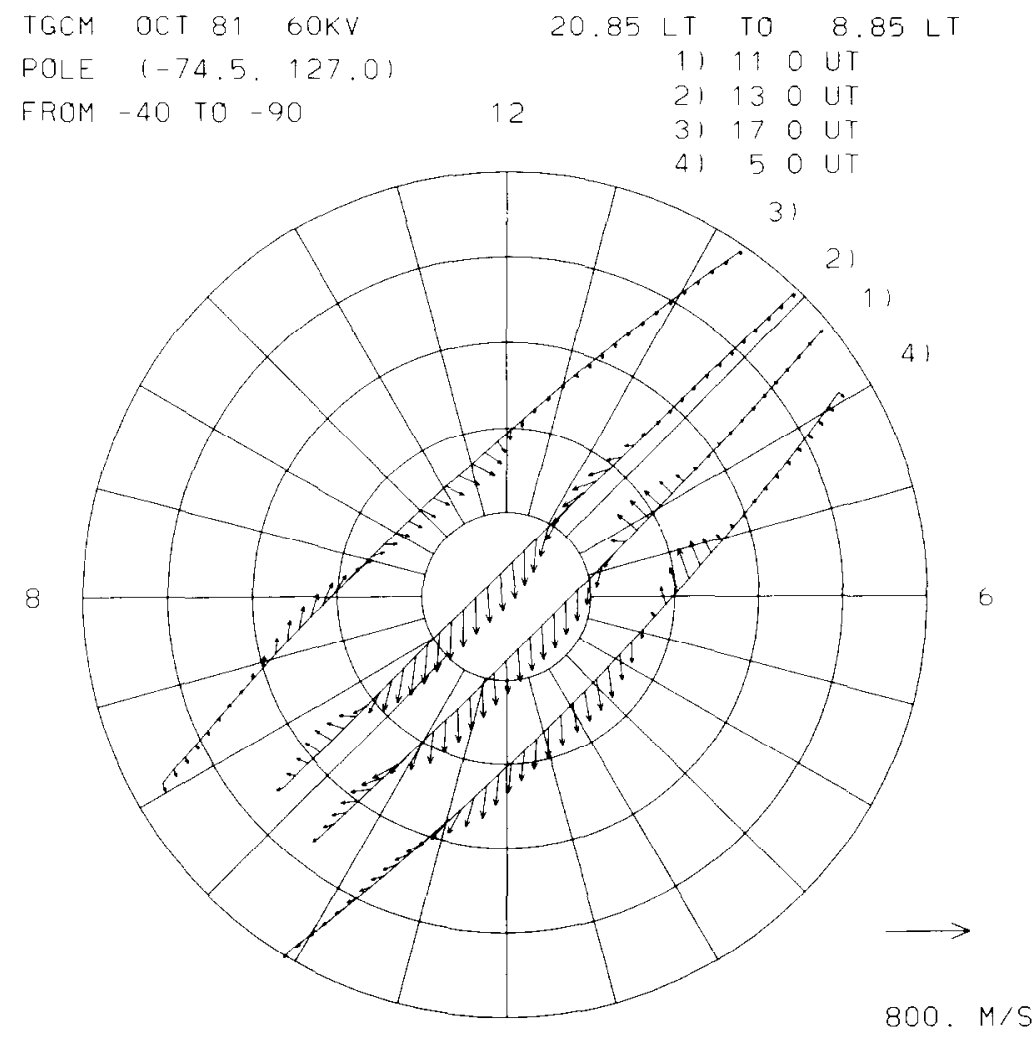

(a)

$$
\begin{aligned}
& \text { O HRS } \\
& \text { Figure } 14 a
\end{aligned}
$$




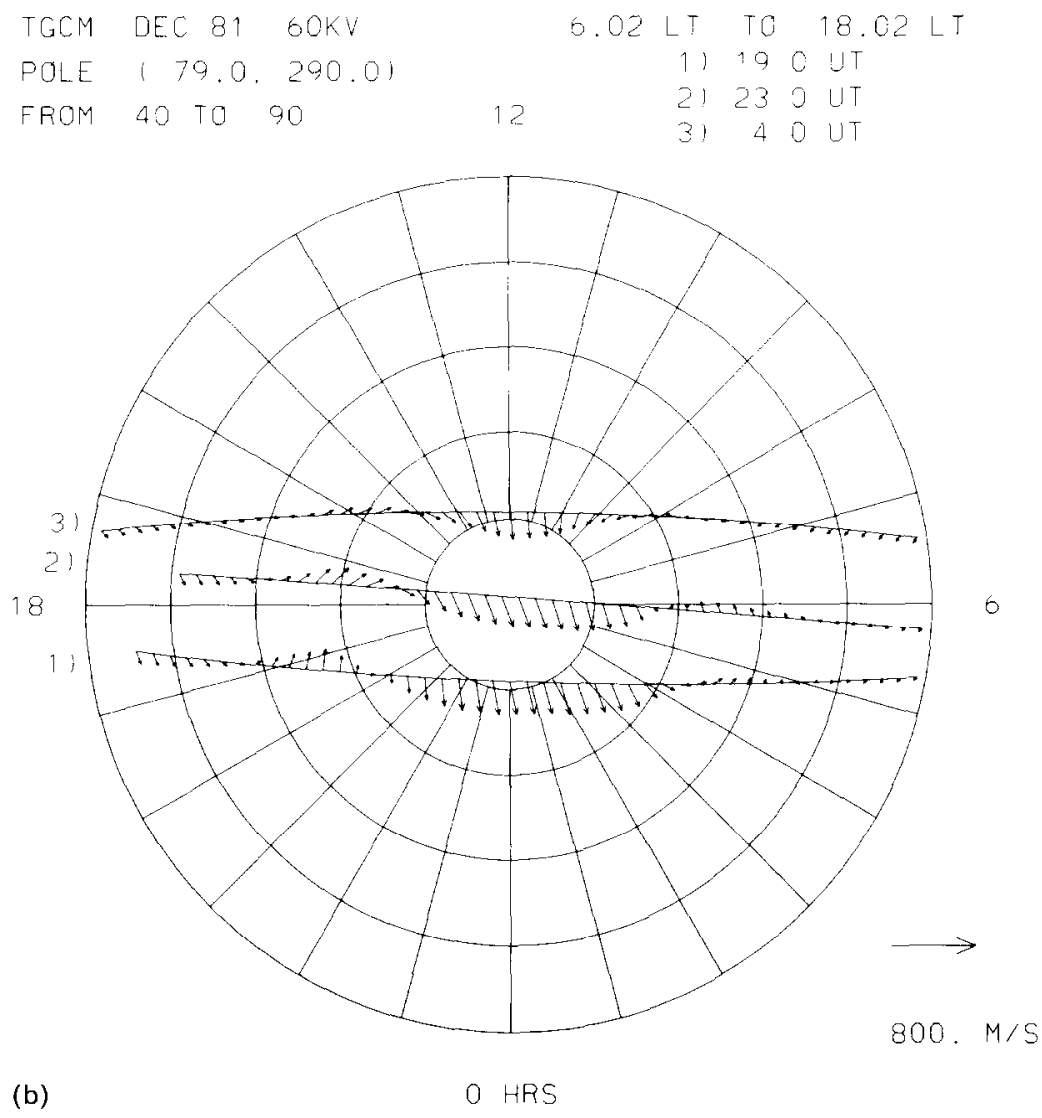

Fig. 14. Polar plots of the Calculated wind vector at $F$-Region ileights along the same $D E$-2 Satellite PATHS SHOWN IN Fig. 12: (a) Winds For the SAME FOUR ORBITS OVER THE SOUTHERN HemisPHERE MaGNETIC POLAR CAP IN OCTOBER AND (b) WINDS FOR THE SAME THREE ORBITS OVER THE NORTHERN MAGNETIC POLAR CAP IN DECEMBER.

on the $F$-region winds at high latitudes. In the sunlit summer polar cap the electron densities are large and the $F$-region winds effectively follow the magnetospheric convection pattern due to the large ion drag momentum source. In the dark winter polar cap the electron densities are lower, primarily maintained by auroral particle precipitation and plasma convected from the daylight ionosphere. The smaller ion drag momentum source results in the neutral wind following but lagging the magnetospheric convection ion drift pattern by a few hours. For very low electron densities the winds decouple from the magnetospheric convection pattern and tend toward the solar-driven circulation pattern.

The results of a linearity analysis using the TGCM show that the total wind structure can be determined at $F$-layer heights to within $10-20 \%$ by a linear superposition of a solar-driven circulation and a magnetospheric convection-driven circulation that have been calculated separately. This suggests that numerically fast linear perturbation models can be developed and used to determine the high-latitude circulation at $F$-region heights and that this circulation can be added to a calculated solar-driven circulation to derive the total fields. The temperature field may also be derived in the summer hemisphere by a linear superposition but more significant errors develop in the winter hemisphere due to Joule heating.

The TGCM-calculated wind pattern was shown to be in reasonable agreement with the $D E-2$ satellitemeasured wind field. The magnitude of the calculated $F$-region winds with a maximum velocity between 400 and $500 \mathrm{~m} \mathrm{~s}^{-1}$ for an assumed cross-tail potential of 60 $\mathrm{kV}$, however, is somewhat smaller than the observed maximum velocity of $500-800 \mathrm{~m} \mathrm{~s}^{-1}$. Better agreement would be obtained by simply increasing the cross-tail potential and ion drift velocities in the magnetospheric convection model. However, such an artificial 

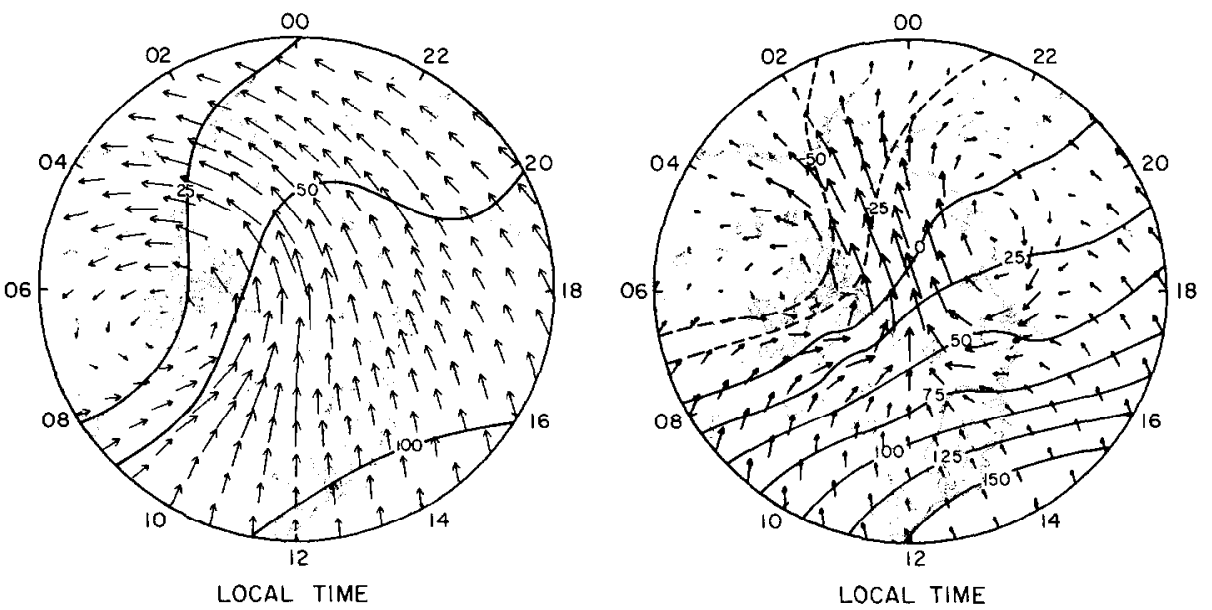

Fig. 15. Polar plots at $Z=1$ of the Calculated wind vectors and Contours of perturbation TEMPERATURE OVER THE NORTHERN HEMISPHERE (WINTER) POLAR CAP FOR THE CASE OF SOLAR HEATING PLUS MAGNETOSPHERIC CONVECTION WITH A CROSS-TAIL POTENTIAL OF $60 \mathrm{kV}$ USING (a) LOW VALUES OF ELECTRON DENSITY IN THE POLAR CAP $\left(\sim 10^{2}-10^{3} \mathrm{~cm}^{-3}\right)$ AND (b) HIGHER CALCULATED ELECTRON DENSITIES THAT ARE CONSISTENT WITH THE CHIU (1975) EMPIRICAL MODEL $\left(\sim 10^{5} \mathrm{~cm}^{-3}\right)$.

The maximum arrow represents (a) $230 \mathrm{~m} \mathrm{~s}^{-1}$ and (b) $340 \mathrm{~m} \mathrm{~s}^{-1}$.

parameterization is not warranted until a better definition of the magnitude of the ion drag momentum source can be obtained from the $D E-2$ satellite plasma measurements.

The TGCM calculations predict significant departures from $F$-region dynamics in the lower thermosphere, below $\sim 150 \mathrm{~km}$, as described for equinox conditions previously by Fuller-Rowell and Rees(1981) and Roble et al.(1982). In the summer hemisphere there is considerable ionization in the $F-1$ and $E$-regions of the ionosphere due to the continuous daylight. As a result magnetospheric convection generates significant Joule heating rates and the ion drag momentum source penetrates to lower altitudes within the ionosphere. In the summer lower thermosphere, the relatively large ion drag induces neutral winds to follow the magnetospheric convection pattern. More significantly, the nonlinear hydro-thermodynamic terms tend to develop a dawn-to-dusk temperature contrast across the polc, with corresponding cyclonic and anticyclonic circulations about these features. The winter lower thermosphere has low electron densities if auroral ionization at those levels is absent. With the electron concentrations used in this paper the Joule heating is about three times smaller in the winter than in the summer hemisphere and the ion drag momentum source is not sufficiently large to alter the solar-driven circumpolar circulation of the cold winter hemisphere. However, lów-level auroral particle precipitation may provide an increased ion drag and so have a significant influence on the dynamic structure of the winter lower thermosphere.

The results of the linearity analysis show significant departures from the TGCM total solution with a linear superposition of solar-driven and magnetospheric convection-driven solutions in the lower thermosphere. The nonlinear interactions between the solarand magnetospheric convection-driven circulations result in the generation of a cold low-pressure cyclonic vortex in both the summer and winter polar caps, which prevents the linear superposition of solutions. Thus it appears that nonlinear models are required for studies of the lower thermosphere.

\section{REFERENCES}

Babcock, R. R. and Evans, J. V. (1979a) Seasonal and solar cycle variations in the thermospheric circulation observed over Millstone Hill. J. geophys. Res. 84, 7348.

Babcock, R. R. and Evans, J. B. (1979b) Effects of geomagnetic disturbances on neutral winds and temperatures in the thermosphere observed over Millstone Hill. J. geophys. Res. 84, 4349.

Bates, H. F. and Roberts, T. D.(1977) The southward midnight surge in $F$-layer wind observed with the Chatanika incoherent scatter radar. J. atmos. terr. Phys. 39, 87.

Chiu, Y. T. (1975) An improved phenomenological model of ionospheric density. J. atmos. terr. Phys. 37, 1563.

Dickinson, R. E., Ridley, E. C. and Roble, R. G. (1975) Meridional circulation in the thermosphere, I. Equinox conditions. J, Atmos. Sci. 32, 1737.

Dickinson, R. E., Ridley, E. C. and Roble, R. G. (1977) 
Meridional circulation in the thermosphere Il. Solstice conditions. J. Atmos. Sci. 34, 178.

Dickinson, R. E., Ridley, E. C. and Roble, R. G. (1981) A threedimensional general circulation model of the thermosphere. J. geophys. Res. 86, 1499.

Emery, B. A. (1978) Neutral thermospheric winds deduced above Millstone Hill II. Seasonal wind variations, 19701971. J. geophys. Res. 83, 5704.

Fuller-Rowell, T. J. and Rees, D. (1980) A three-dimensional, time-dependent global model of the thermosphere. $J$. Atmos. Sci. 37, 2545.

Fuller-Rowell, T. J. and Rees, D. (1981) A three-dimensional, time-dependent simulation of the global dynamical response of the thermosphere to a geomagnetic substorm. $J$. atmos. terr. Phys. 43, 701.

Hays, P. B., Meriwether, J. W. and Roble, R. G. (1979) Nighttime thermospheric winds at high latitudes. $J$. geophys. Res. 84, 1905.

Hays, P. B., Killeen, T. L. and Kennedy, B. C. (1981) The Fabry-Perot interferometer on Dynamics Fxplorer. Space Sci. Instr. 5, 395.

Hedin, A. E., Salah, J. E., Evans, J. V., Reber, C. A., Newton, G. P., Spencer, N. W., Kayser, D. C., Alcaydé, D., Bauer, P., Cogger, L. and McClure, J. P. (1977a) A global thermospheric model based on mass spectrometer and incoherent scatter data, MSIS 1, $\mathrm{N}_{2}$ density and temperalure. J. geophys. Res. 82, 2139.

Hedin, A. E., Reber, C. A., Newton, G. P., Spencer, N. W., Brinton, H. C., Mayr, H. G. and Potter, W. E. (1977b) A global thermospheric model based on mass spectrometer and incoherent scatter data, MSIS 2, composition. $J$. geophys. Res. 82, 2148.

Heppner, J. P. and Miller, M. L. (1982) Thermospheric winds at high latitudes from chemical release observations. $J$. geophys. Res. 87, 1633.

Hernandez, G. and Roble, R. G. (1976) Direct measurements of nightime thermospheric winds and temperatures. 1. Seasonal variations during geomagnetic quiet periods. $J$. geophys. Res. 81, 2065.

Hoffman, R. A., Hogan, G. D. and Maehl, R. C. (1971) Dynamics Explorer spacecraft and ground operations systems. Space Sci. Instr. 5, 349.

Killeen, T. L., Hays, P. B., Spencer, N. W. and Wharton, L. E. (1982) Neutral winds in the polar thermosphere as measured from Dynamics Explorer. Geophys. Res. Lett. 9 , 957.

Killeen, T. L., Hays, P. B., Spencer, N. W. and Wharton, L. E. (1983) Neutral winds in the polar thermosphere as measured from Dynamic's Explorer. Adv. Space Res. 2, 133.

Mayr, H. G. and Volland, H. (1972) Theoretical model for the latitude dpendence of the thermospheric annual and semiannual variations. J.geophys. Res. 77, 6774.

Meriwether, J. W., Heppner, J. P., Stolarik, J. D. and Wescott,
E. M. (1973) Neutral winds above $200 \mathrm{~km}$ at high latitudes. J. geophys. Res. 78, 6643 .

Nagy, A. F., Cicerone, R. J., Hays, P. B., McWatters, K. C., Meriwether, J. W., Belon, A. E. and Rino, C. L. (1974) Simultaneous measurement of ion and neutral motions by radar and optical techniques. Radio Sci.9, 315.

Oliver, W. L. (1980) Improved Millstone Hill exospheric temperature measurements: Evidence for a seasonal variation of the magnetic activity effect. J.geophys. Res. 85, 4237.

Rees, D., Fuller-Rowell, T. J. and Smith, R. W. (1980) Measurements of high latitude thermospheric winds by rocket and ground-based techniques and their interpretation using a three-dimensional time-dependent dynamical model, Planet. Space Sci. 28, 919.

Roble, R. G., Dickinson, R. E. and Ridley, E. C.(1977) Seasonal and solar cycle variations of the zonal mean circulation in the thermosphere. J. geophys. Res. 82, 5493.

Roble, R. G., Dickinson, R. E. and Ridley, E. C. (1982) The global circulation and temperature structure of the thermosphere with high latitude plasma convection. $J$. geophys. Res. 87, 1599.

Sipler, D. P., Lukkala, B. B. and Biondi, M. A. (1982) FabryPerot determinations of midlatitude $F$-region neutral winds and temperatures from 1975 to 1979. Planet. Space Sci. 30, 1025 .

Sojka, J. J., Railı, W. J. and Schunk, R. W. (1979) Elfect of displaced geomagnetic and geographic poles on highlatitude plasma convection and ionospheric depletions. $J$. geophys. Res. 84, 5943.

Sojka, J.J., Raitt, W. J.and Schunk, R. W.(1980) A comparison of model predictions for plasma convection in the northern and southern polar regions. J. geophys. Res. 85, 1762 .

Spencer, N. W., Wharton, L. E., Niemann, H. B., Hedin, A. E., Carignan, G. R. and Maurer, J. C. (1981) The Dynamics Explorer wind and temperature spectrometer. Space Sci. Instr. 5, 417.

Spencer, N. W., Wharton, L. W., Carignan, G. R. and Maurner, J. C. (1982) Thermosphere zonal winds, vertical motions and temperature as measured from Dynamics Explorer. Geophys. Res. Lett. 9, 953.

Straus, J. M. and Christopher, L. A. (1979) Dynamical effects on the global distribution of thermospheric atomic oxygen. J. geophys. Res. 84, 1241.

Straus, J. M., Creekmore, S. P., Harris, R. M. and Ching, B. K. (1975) Effects of heating at high latitudes on global thermospheric dynamics. J. atmos. terr. Phys. 37, 1545.

Volland, H. (1975) Models of global electric fields within the magnetosphere. Ann. Geophys. 31, 154.

Volland, H. (1978) A model of magnetospheric electric convection field. J. geophys. Res. 83, 2695.

Volland, H. (1979a) Semiempirical models of magnetospheric electric fields. Quantitative Modeling of Magnetospheric Processes, Geophys. Monograph Vol. 21, 261. 